\title{
Rock abundance on Mars from the Thermal Emission Spectrometer
}

\author{
S. A. Nowicki ${ }^{1}$ and P. R. Christensen ${ }^{1}$ \\ Received 22 July 2006; revised 21 September 2006; accepted 27 November 2006; published 17 May 2007.
}

[1] Nighttime infrared spectral observations returned from the Mars Global Surveyor Thermal Emission Spectrometer (TES) are well suited for determining the subpixel abundance of rocks on the surface of Mars. The algorithm used here determines both the areal fraction of rocky material and the thermal inertia of the fine-grained nonrock component present on the surface. Rock is defined as any surface material that has a thermal inertia $\geq 1250 \mathrm{~J} \mathrm{~m}^{-2} \mathrm{~K}^{-1} \mathrm{~s}^{-1 / 2}$. This can be bedrock, boulders, indurated sediments, or a combination of these on a surface mixed with finer-grained materials. Over 4.9 million observations were compiled to produce the 8 pixels per degree global rock abundance and fine-component inertia maps. Total coverage is $\sim 45 \%$ of the planet between latitudes -60 and 60 . Less than $1 \%$ of the planet has rock abundances greater than $50 \%$, and $\sim 7 \%$ of the mapped surface has greater than $30 \%$ rocks. Rocky regions on Mars correspond primarily to the high-inertia surfaces observed in thermal inertia data sets. The fine-component inertia data set is used to identify high-inertia exposures that contain few rocks and more homogeneous materials.

Citation: Nowicki, S. A., and P. R. Christensen (2007), Rock abundance on Mars from the Thermal Emission Spectrometer, J. Geophys. Res., 112, E05007, doi:10.1029/2006JE002798.

\section{Introduction}

[2] The surface layer of Mars has evolved through a combination of global, regional and local processes. The original mode of deposition or erosion often produces the morphology that can be observed in orbital imagery, but many surfaces have been modified by subsequent processes such as dust mantling or aeolian erosion. As a result, the materials exposed on the surface may not be directly related to the morphology. The materials present in the upper few centimeters provide information about the processes that have most recently been at work, and can be characterized using remotely sensed thermophysical measurements such as thermal inertia and rock abundance.

[3] Thermal inertia represents the ability of near-surface materials to absorb solar energy during the day, conduct it into the subsurface, and then release that energy during the night. It can be used to infer an average grain size of the upper few centimeters of the surface, and determine whether a surface is made up of bedrock, sand, or a thick layer of fine, unconsolidated dust [Neugebauer et al., 1971]. Thermal inertia is a physical property based upon a thermal model of a conductive material heated by insolation and cooled by radiation to space. The original models were based upon the studies of lunar temperature variations by Wesselink [1948] and Jaeger [1953]. Further development of the models for Mars included surface-atmosphere energy transfer [Leovy, 1966], atmospheric back radiation [Neugebauer et al., 1971], surface emissivity variations [Kieffer et al.,

\footnotetext{
${ }^{1}$ Department of Geological Sciences, Arizona State University, Tempe, Arizona, USA.

Copyright 2007 by the American Geophysical Union. 0148-0227/07/2006JE002798\$09.00
}

1973], $\mathrm{CO}_{2}$ frost and blocky surfaces [Kieffer et al., 1977], variability of atmospheric back radiation [Haberle and Jakosky, 1991], effects of a radiative-convective atmosphere [Hayashi et al., 1995], and single-point temperature observations [Jakosky et al., 2000; Mellon et al., 2000]. Global data sets of the thermal inertia of Mars have been derived using IRTM data [Kieffer et al., 1977; Palluconi and Kieffer, 1981; Christensen and Malin, 1988] and TES observations [Jakosky et al., 2000; Mellon et al., 2000; Putzig et al., 2005]. High-resolution data sets of small areas of the planet have been derived with Phobos-2 TERMOSCAN data [Selivanov et al., 1989; Betts et al., 1995], and Mars Odyssey THEMIS images [Fergason and Christensen, 2003].

[4] Although bulk thermal inertia values can be precisely calculated, this parameter is not sufficient to characterize surfaces that have a mixture of materials with different thermal inertias [Christensen, 1982]. As was seen in Viking, Pathfinder, and MER landing site images, the Martian surface can contain a wide range of particles from dust to large blocks [Mutch et al., 1976a, 1976b; Golombek et al., 1997; Squyres et al., 2004a, 2004b]. This suggests that for much of Mars there is often more than one type of material exposed at the surface. Some exceptions are the lowest thermal inertia regions on the planet, which are likely to be covered with a thick, relatively homogeneous layer of dust [Kieffer et al., 1973, 1977; Palluconi and Kieffer, 1981; Jakosky, 1986; Christensen, 1986b].

[5] In a single field of view, rocks, sand, and dust will have different temperatures as a function of the time of day due to the variations in thermal inertia. The calculated bulk thermal inertias of mixed surfaces will also change as a function of the time of day [Kieffer et al., 1977], making it impossible to characterize a mixed surface using only one 
temperature observation at one time of day. Increasing the number of observations by including more wavelengths makes it possible to distinguish mixtures of temperature components. Thermal infrared emission from multiple temperature components produces a complex composite spectrum [Christensen, 1982]. By modeling this spectrum, we can determine the subpixel abundance of materials with different thermal inertias, and specifically calculate the amount of rocky material exposed in each observation. This information has been used in a number of science and engineering applications, including interpreting subsurface properties [Jakosky and Christensen, 1986], comparing surface properties with atmospheric circulation models [Greeley et al., 1993], and assessing the hazards that rocks on a surface may present to a lander mission [Golombek and Rapp, 1997; Golombek et al., 2003a].

[6] Nighttime spectral observations returned from TES are well suited for determining the subpixel rock abundance on the surface of Mars. While daytime observations are dominated by the albedo and emissivity, which are controlled by the mineralogic composition of surface materials, nighttime emission is controlled almost entirely by the thermophysical properties [Neugebauer et al., 1971; Kieffer et al., 1973]. The algorithm used here employs nighttime spectral observations to determine both the areal fraction of rocks and the thermal inertia of the low-temperature nonrock component. These methods were developed using Viking Orbiter IRTM data [Christensen, 1982], and the results were presented in a $1^{\circ} \times 1^{\circ}$ global map [Christensen, 1986a]. TES observations at $3 \times \sim 6 \mathrm{~km}$ provide over $200 \times$ the spatial resolution of the IRTM map. These new data provide not only a higher-resolution data set but also allow for an improved atmospheric correction and better isolation of surface compositional variations.

[7] In this paper, thermal inertia will be given in units of $\mathrm{J} \mathrm{m}^{-2} \mathrm{~K}^{-1} \mathrm{~s}^{-1 / 2}$. To convert to the historical $10^{-3} \mathrm{cal} \mathrm{cm}^{-2}$ $\mathrm{K}^{-1} \mathrm{~s}^{-1 / 2}$, divide by a factor of 41.86 . Local time is presented as $\mathrm{H}$, where $24 \mathrm{H}$ equals one Martian day (24.7 Earth hours). Seasons are given as aerocentric longitude of the Sun $\left(\mathrm{L}_{\mathrm{s}}\right)$, where one year is $360^{\circ}$, and vernal equinox is at $\mathrm{L}_{\mathrm{s}}=0$. Albedo values are assumed to be Lambert albedo, given as the fraction of reflected to incident solar radiance.

\section{Data Set}

[8] The TES instrument onboard the Mars Global Surveyor (MGS) spacecraft was designed to determine the composition, temperature, and physical properties of the surface and atmosphere of Mars [Christensen et al., 1998, 2001]. The TES instrument consists of a Fourier transform Michelson interferometric spectrometer, which collects hyperspectral thermal infrared radiance from 5.8 to $50 \mu \mathrm{m}$; a visible/near-infrared bolometric radiometer which collects integrated solar reflected radiance over $0.3-2.9 \mu \mathrm{m}$; and a broadband thermal infrared radiometer that measures the emitted radiance from 5.1 to $150 \mu \mathrm{m}$.

[9] The MGS spacecraft is in a $\sim 2$ hour Sun-synchronous polar orbit. Each orbit track is a series of north-south trending observations from the $3 \times 2$ array of detectors. The instantaneous field of view of each detector is $3 \times 3 \mathrm{~km}$ on the surface of Mars, but due to spacecraft motion the observed radiance is integrated over a longer area in the along-track dimension, resulting in a footprint of $\sim 6 \times$ $3 \mathrm{~km}$ for each detector. Observations are made so that the daytime equator crossing occurs at a local time of approximately $14.5 \mathrm{H}$, and night crossing at $2.5 \mathrm{H}$. For this investigation, we only use nadir-pointed nighttime data between -60 and 60 latitudes. Higher-latitude observations are problematic for calculating themophysical properties due to the low temperatures, high solar incidence angle, variable day/night lengths, and the seasonal presence of $\mathrm{CO}_{2}$ frost.

[10] To reduce the downlinked data volume, a portion of the nighttime spectral observations were acquired using spectral selection and averaging masks [Christensen et al., 2001]. A number of masks were used throughout the mission, some of which did not collect data in the spectral ranges useful for this investigation, limiting the total number of applicable observations from the full data set. Results presented here were calculated from data starting at the beginning of mapping phase of the MGS mission at $\mathrm{L}_{\mathrm{s}}=$ $104^{\circ}$ (March 1998) and extending for over a Mars year to $\mathrm{L}_{\mathrm{s}}=137^{\circ}$ (March 2001). Although TES continued to collect data, instrument signal degradation due to spacecraft vibrations has made later observations increasingly unsuitable for this investigation.

\section{Theory}

[11] The radiance of Mars as observed by TES can be described by the form of the radiative transfer equation:

$$
\mathrm{R}_{\mathrm{obs} \lambda}=\mathrm{R}_{\text {surf } \lambda} \mathrm{e}^{-\tau \mathrm{o}(\lambda) / \mu}+\int_{0}^{\tau} \mathrm{R}_{\mathrm{BB}}[\mathrm{T}(\mathrm{p}), \lambda] e^{-\tau(\lambda, \mathrm{p}) / \mu} \delta \tau
$$

In this equation, $\mathrm{R}_{\mathrm{obs}}$ is the measured radiance at the sensor; $\mathrm{R}_{\text {surf }}$ is the total radiance of the surface; $\tau \mathrm{o}(\lambda, \mathrm{p})$ is the normal opacity profile as a function of wave number and pressure; and $\mu$ is the cosine of the emission angle. The integral is taken through the atmosphere from the spacecraft $(\tau)$ to the surface $(0) ; \mathrm{R}_{\mathrm{BB}}$ is the radiance of a blackbody at the temperature described by $\mathrm{T}(p)$, the atmospheric temperature profile. The first term describes the absorption of surface radiation by the atmosphere, and the second term accounts for the upwelling radiance of the atmosphere and suspended aerosols [Smith et al., 2000]. This model assumes that there is no scattering from atmospheric aerosols, and that the gases and aerosols are well mixed throughout the atmospheric column [Smith et al., 2000].

[12] The radiance of the surface $\left(\mathrm{R}_{\operatorname{surf} \lambda}\right)$, is the integrated radiance of all the components present on the surface. Each component is defined as an isothermal surface that radiates energy as a blackbody, which is a theoretical surface that absorbs all incident radiance and emits it without any spectral features. The emitted radiance of a single blackbody surface is described by the Planck function:

$$
R_{B B}[T, \lambda]=2 h c^{2} \lambda^{-5}\left(e^{-(h c / \lambda k T c)}-1\right)^{-1}
$$

$\mathrm{R}_{\mathrm{BB}}[\mathrm{T}, \lambda]$ is the blackbody radiance of a surface component at temperature T; $h$ is the Planck constant; $c$ is the speed of light, and $k$ is the Boltzmann's constant. As can be 


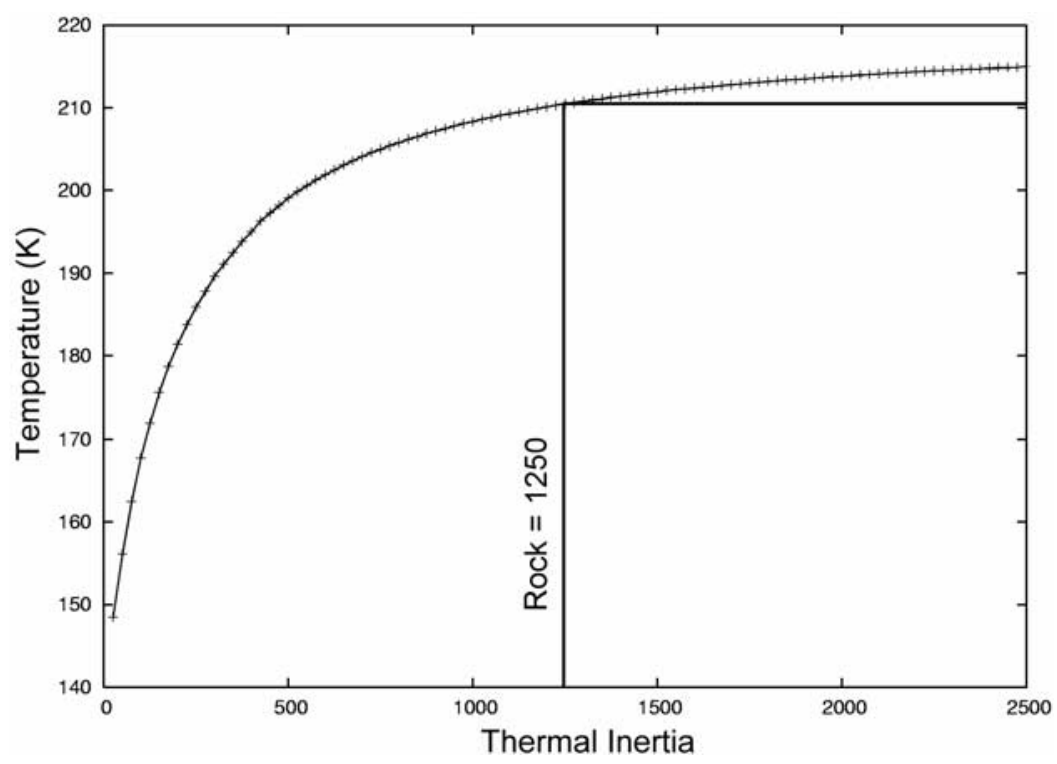

Figure 1. Representative model temperature curve as a function of thermal inertia $\left(\mathrm{J} \mathrm{m}^{-2} \mathrm{~K}^{-1} \mathrm{~s}^{-1 / 2}\right)$. Time of day is $3.5 \mathrm{H}$ and season is Ls 90 . Temperature is highly dependent upon inertia in the lower inertia ranges and flattens out above $\sim 1000$. This temperature change is directly related to the increasing dominance of solid conduction in the material. Since the temperature does not change significantly with inertias over 1250 , we simplify by assuming a single inertia value for the highest temperatures.

determined from equation (2), the only property needed to describe the radiance from a theoretical blackbody surface component is the temperature.

[13] Modeling the temperature of a surface component requires knowing two characteristics. The first is the amount of solar radiation the surface will absorb, expressed in terms of bolometric albedo $(A=1-\mathrm{R})$ where $\mathrm{R}$ is the reflectance. The second is the resistance of a surface to heat up due to subsurface conduction, described in the term thermal inertia (I). Kieffer et al. [1973] showed in model data that increasing the albedo of a surface decreases the temperature at all times throughout the day, with the largest effect at midday, and diminishing until dawn. Thus daytime observations depend strongly on the albedo, while predawn temperatures depend almost exclusively on the thermal inertia.

[14] Thermal inertia is a physical property of a material that controls the amplitude of the diurnal temperature curve. We use it to model the surface temperature of a component at any season and local time. Thermal inertia $(I)$ is calculated as a function of a material's density $(\rho)$, specific heat $\left(\mathrm{c}_{\rho}\right)$, and conductivity $(k)$ as follows:

$$
I=\sqrt{k \rho c_{\rho}}
$$

The density and specific heat for common geologic materials vary by less than a factor of two. Most differences in thermal inertia can be interpreted as variations in conductivity, which can vary by an order of magnitude, and is strongly dependent on particle size and only weakly dependent on composition [Neugebauer et al., 1971].

[15] Variations in conductivity are controlled by the physical constraints on the propagation of a thermal wave through naturally occurring geologic materials [Wechsler and Glaser, 1965; Wechsler et al., 1972]. Conduction $(k)$ of the thermal wave occurs via three primary heat transfer mechanisms:

$$
k=k_{g}+k_{s}+k_{r}
$$

In this equation, $\mathrm{k}_{\mathrm{g}}$ is the heat transfer due to the gas conduction across open spaces containing a gaseous medium; $\mathrm{k}_{\mathrm{s}}$ is the solid conduction as described by the physical properties of the minerals; and $\mathrm{k}_{\mathrm{r}}$ is the heat transfer due to radiation and reabsorption of photons across void space between grains. Under Martian conditions, the heat transfer due to radiation $\left(\mathrm{k}_{\mathrm{r}}\right)$ is negligible compared to the other two terms, while the gas conduction $\left(\mathrm{k}_{\mathrm{g}}\right)$ in particulate materials is highly dependent on the atmospheric pressure and pore space, and the solid conduction varies insignificantly with common geologic materials [Neugebauer et al., 1971; Kieffer et al., 1973]. Thus, under Martian conditions, the gas conduction $\left(\mathrm{k}_{\mathrm{g}}\right)$ becomes the dominant term controlling variations in heat transfer.

[16] The change in predawn surface temperature as a function of inertia is a nonlinear function (Figure 1). In the low-inertia range, temperature is highly dependent on inertia, but becomes less so at higher inertias. At the highest inertias the temperature curve flattens with increased inertia. This change in the temperature curve is due to the thickness of the conductive material approaching the thermal skin depth [Christensen, 1982], beyond which, there is little temperature change with increased inertia.

[17] The diurnal skin depth $(z)$ is a measure of the effective depth of the solar heat wave, and is a function of the thermal properties of material and the period $(\mathrm{P})$ of the wave:

$$
z=\sqrt{k\left(\rho c_{\rho}\right)^{-1} P / \pi}
$$


The skin depth is defined as the distance from the surface at which the temperature change drops by a factor of e. Effectively, this is the depth at which the diurnal wave stops being the dominant factor controlling the subsurface temperature. Inversely, the subsurface energy at several diurnal skin depths does not contribute to the nighttime surface temperature. The diurnal skin depth for common geologic materials subject to solar insolation on Mars $(\mathrm{P}=$ 24.7 Earth hours) is about $15 \mathrm{~cm}$ for common solid minerals. This threshold corresponds to an inertia of $\sim 1250 \mathrm{~J} \mathrm{~m}^{-2} \mathrm{~K}^{-1} \mathrm{~s}^{-1 / 2}$. Above this inertia and below this depth, the temperature does not vary significantly.

[18] This threshold represents a significant change in geologic and thermal properties, which allows for the number of physical variables to be simplified when modeling a surface. Any component that is at a temperature greater than that of a surface with inertia $1250 \mathrm{~J} \mathrm{~m}^{-2} \mathrm{~K}^{-1} \mathrm{~s}^{-1 / 2}$ can be modeled as a solid rock at least $15 \mathrm{~cm}$ in diameter. Observations made by the Spirit Mini-TES instrument in Gusev crater are the first in situ measurements of the thermal properties of materials under Martian conditions [Christensen et al., 2004], and result in a lower-limit thermal inertia of $1200 \mathrm{~J} \mathrm{~m}^{-2} \mathrm{~K}^{-1} \mathrm{~s}^{-1 / 2}$ for a $0.75 \mathrm{~m}$ diameter basaltic rock [Fergason et al., 2006]. While our assumed threshold thermal inertia is consistent with the Mini-TES observations, the IRTM rock abundance algorithm results have been shown to be relatively insensitive to the assumed rock thermal inertia [Golombek et al., 2003a].

[19] While we can constrain the temperature of rock at any given time and season, the temperatures of other surface components can vary significantly on a planetary surface. There can also be more than two different components in a field of view. In order to reasonably model real surfaces, we integrate the radiance from the lower-temperature component and derive a single kinetic temperature. That temperature is fit to model curves to determine an average fine-component thermal inertia. We refer to this composite thermal inertia as the fine-component inertia because the material must be particulate with grains significantly smaller than the diurnal skin depth, as determined in laboratory studies [Wechsler and Glaser, 1965; Wechsler et al., 1972; Presley and Christensen, 1997]. The radiance from a surface that contains both rocks and particulate materials can be described as the areal fraction of the radiance of each component.

[20] The compositional variations on Mars are the last heterogeneity that influences the radiance from the surface $\left(\mathrm{R}_{\text {surf } \lambda}\right)$ in equation (1). The vibrational absorptions of the minerals present reduce the total radiance from a theoretical blackbody surface as a function of the emissivity. We take both the emissivity of the entire surface and the fractions of the surface components into account in the following equation:

$$
R_{\text {surf } \lambda}=\varepsilon \lambda\left(R_{B B}\left[T_{\text {rock }}, \lambda\right] \alpha\right)+R_{B B}\left[T_{f c}, \lambda\right](1-\alpha)
$$

In this equation, $\mathrm{T}_{\text {rock }}$ is the component at the temperature modeled by the inertia of rock, $\mathrm{T}_{\mathrm{fc}}$ is the fine component temperature, $\varepsilon$ is the emissivity, and $\alpha$ is the fraction area of the rock temperature component.
[21] The full equation for a surface simplified to two temperature components can be written in the following form:

$$
R_{o b s \lambda}=\varepsilon_{1 \lambda}\left(R_{B B}\left[T_{1}, \lambda\right] \alpha\right)+\varepsilon_{2 \lambda} R_{B B}\left[T_{2}, \lambda\right](1-\alpha)+R_{a t m \lambda}+I R_{\lambda}
$$

The emissivities of the components $\left(\varepsilon_{1}\right.$ and $\left.\varepsilon_{2}\right)$ and the atmospheric radiance $\left(R_{\mathrm{atm}}\right)$ are determined from daytime TES observations. The internal radiance of the instrument $(I R \lambda)$ is determined from space observations, and the temperature of the rock component $\left(\mathrm{T}_{\text {rock }}\right)$ is calculated using the assumed inertia of rock at $1250 \mathrm{~J} \mathrm{~m}^{-2} \mathrm{~K}^{-1} \mathrm{~s}^{-1 / 2}$.

[22] In the following sections, we outline the method for simplifying the calculation in brightness temperature space, and determining the atmospheric and surface emissivity values. Finally, we describe the rock abundance algorithm as applied to TES data in section 4.6.

\section{Methods}

\subsection{Rock Abundance Algorithm}

[23] It has been demonstrated through compositional analysis that thermal infrared spectra represent linear combinations of the areal abundance of the individual surface components [Gillespie, 1992; Thompson and Salisbury, 1993; Ramsey and Christensen, 1998; Ramsey et al., 1999; Ramsey and Fink, 1999; Feeley and Christensen, 1999; Hamilton and Christensen, 2000]. This relationship also applies to the radiant contribution of components at different temperatures. The radiance spectrum of an anisothermal surface cannot be modeled using a blackbody at a single temperature, but rather with a combination of Planck curves in radiance space [Christensen, 1982, 1986a]. A $50 / 50$ mixture of blackbodies at $250 \mathrm{~K}$ and $150 \mathrm{~K}$ do not produce a curve that can be described by the Planck function at a single temperature of $200 \mathrm{~K}$ (Figure 2a). Instead, the mixed spectrum is a unique linear combination of two blackbodies. When these radiance spectra are converted to brightness temperature (Figure $2 \mathrm{~b}$ ), the deviation from the Planck function is made apparent. Effectively, the higher-temperature component contributes more energy to the short-wavelength portion of the spectrum, while the low-temperature component contributes more to the longer wavelengths. The variation at different wavelengths is what allows the separation of multiple components in anisothermal surfaces. When isolated from other spectral features, this effect can be used to determine the fraction of the different temperature components, specifically the rock abundance $(\alpha)$.

[24] In this study, rock is defined as any material with a thermal inertia above $\sim 1250 \mathrm{~J} \mathrm{~m}^{-2} \mathrm{~K}^{-1} \mathrm{~s}^{-1 / 2}$, following Christensen [1986a]. This represents a minimum $\sim 15 \mathrm{~cm}$ rock diameter for common consolidated materials on Mars. This material can be bedrock, boulders, indurated sediments, or a combination of these on a surface mixed with finer-grained materials. The rock abundance is the percentage of the field of view that is covered in material with a thermal inertia of rock. This calculation makes no assessment of the surface roughness or composition of the rocky material. 


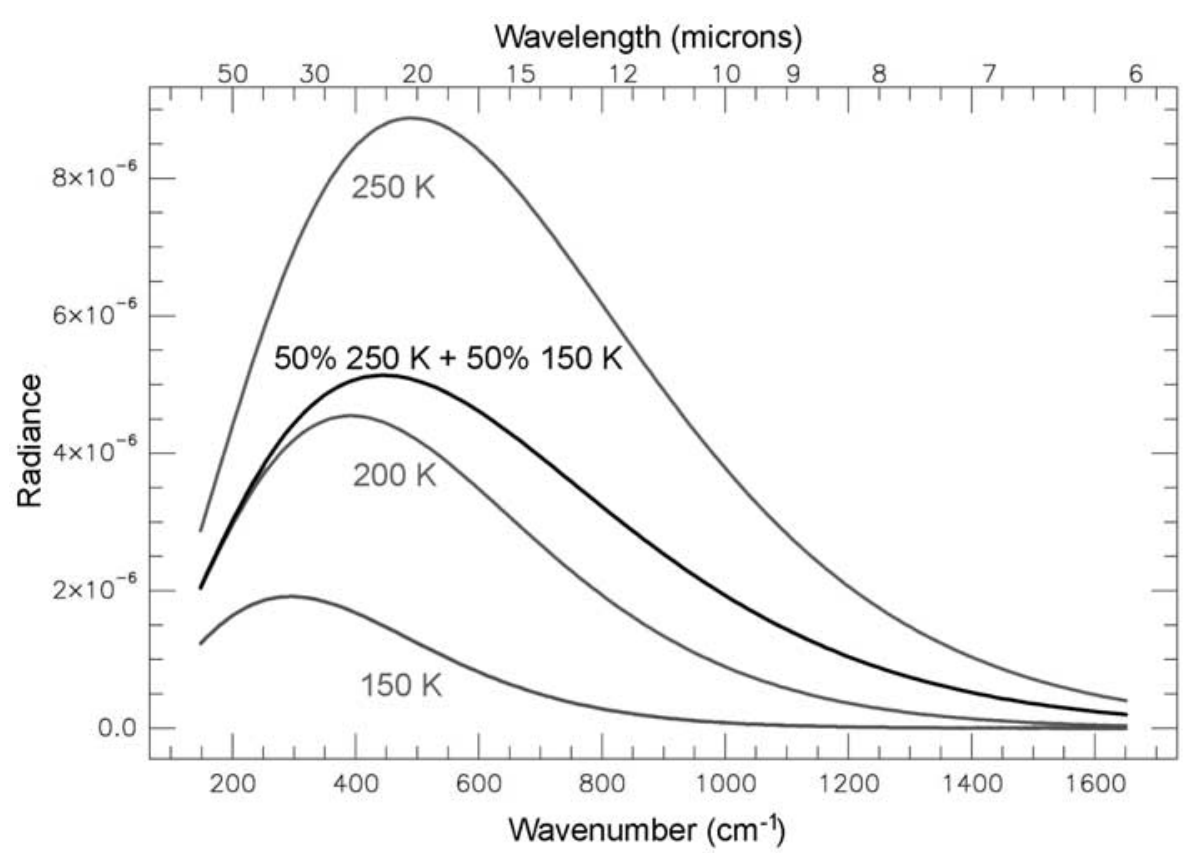

(a)

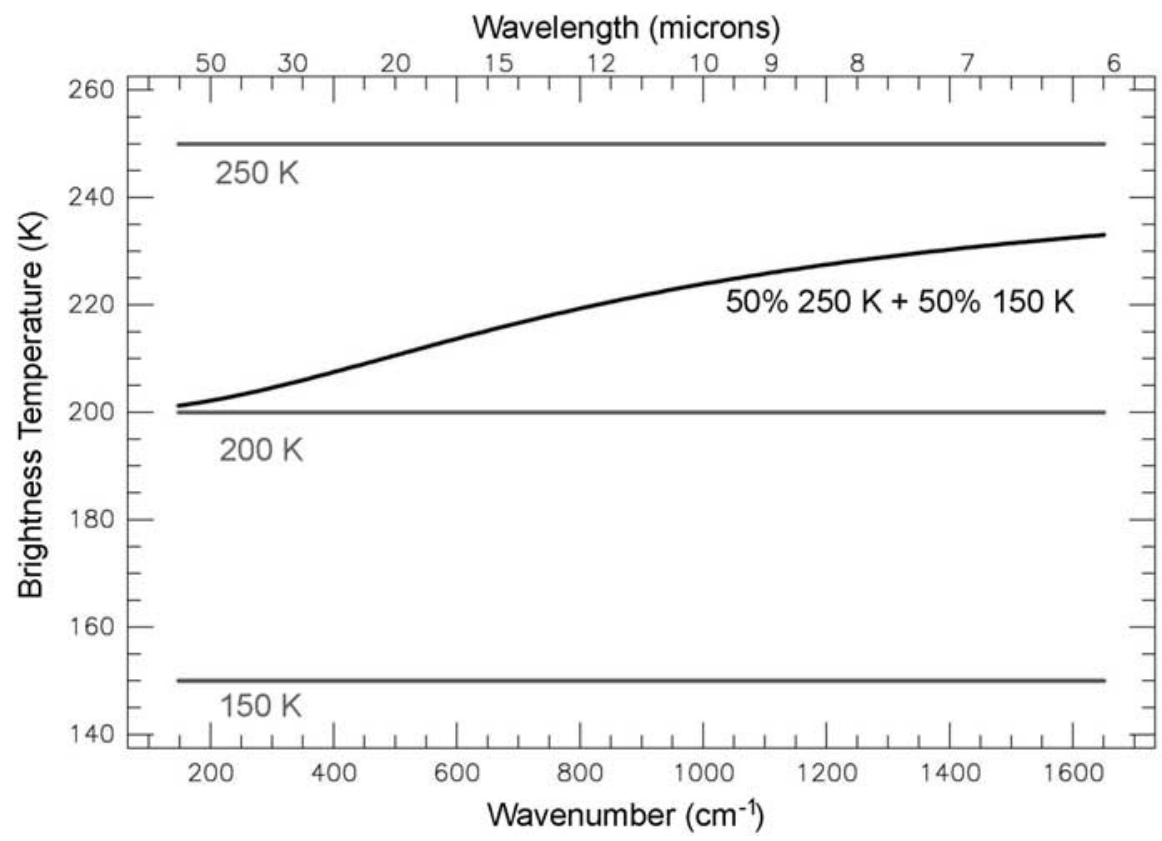

(b)

Figure 2. Plots of modeled spectra illustrating anisothermal spectral deviance. (a) Modeled radiance over the TES spectral wavelength range. The 150, 200, and 250 curves are blackbodies at those temperatures. The black curve is the additive result of $50 \% 250 \mathrm{~K}$ and $50 \% 150 \mathrm{~K}$ Planck curves. (b) Modeled spectra converted to brightness temperature. The wavelength-dependent temperature change in the black curve is the anisothermal spectral deviation.

[25] The rock abundance calculation used here is similar to the spectral difference model developed for use with IRTM data [Christensen, 1982], although there are differences in the wavelength channels used and the atmospheric and surface emissivity corrections. We integrate the spectral radiance into two-channel brightness temperatures and use the difference between these channels and the absolute temperature in each channel $\left(\mathrm{T}_{\lambda}\right)$ in the model. The optimal wavelengths for decreasing the effects of the atmosphere, surface emissivity, instrument spectral masks, and maximiz- ing signal to noise in the TES spectral range have band centers at $30 \mu \mathrm{m}\left(250-400 \mathrm{~cm}^{-1}\right)$ and $9 \mu \mathrm{m}(1110-$ $1200 \mathrm{~cm}^{-1}$ ) (Figure 3). These wavelength channels are effectively equivalent to the 7 and $20 \mu \mathrm{m}$ IRTM bands used by Christensen [1982, 1986a]. The brightness temperature are written as $T_{9}$ and $T_{30}$ for the integrated brightness temperature in the 9 and $30 \mu \mathrm{m}$ channels, respectively. Christensen [1982, 1986a] used the albedo of the surface to assume an emissivity for surfaces viewed with IRTM. Here 


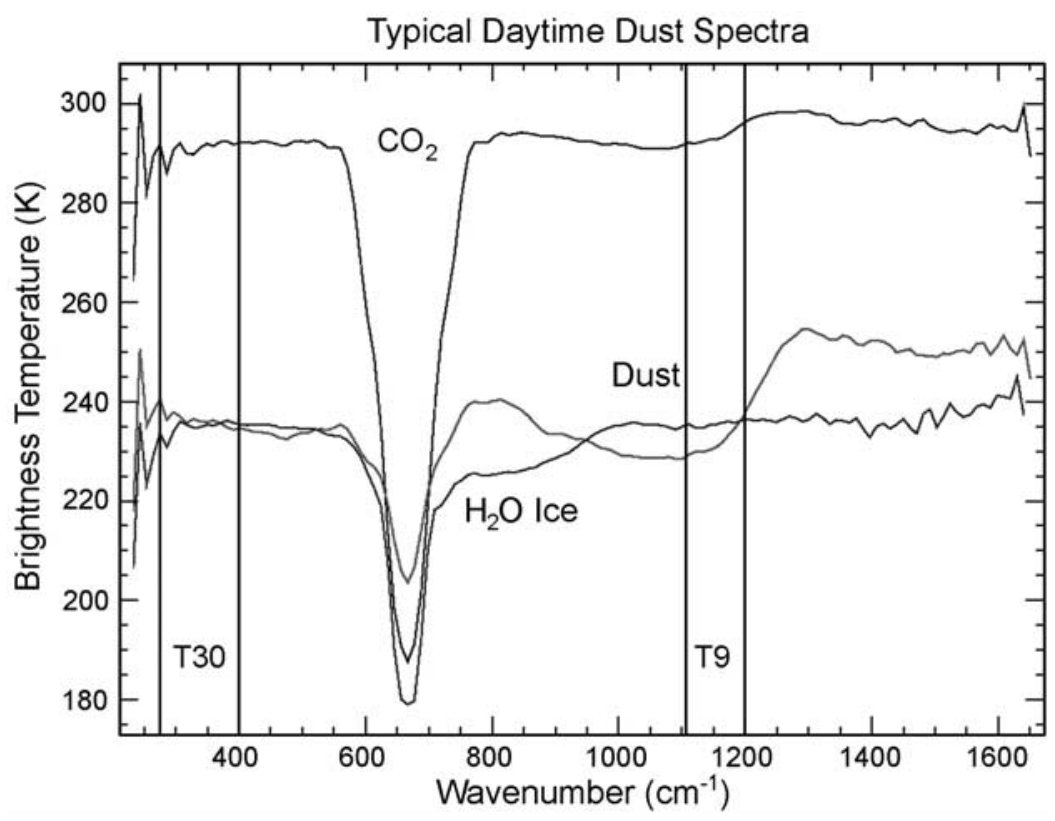

Figure 3. Typical daytime TES spectra indicative of specific atmospheric conditions [after Smith et al., 2000]. The major absorptions due to atmospheric components are labeled. The wavelengths of the integrated TES channels used in this study are shows with band centers at 30 and $9 \mu \mathrm{m}$, labeled T30 and T9, respectively.

we use TES daytime measurements of the surface emissivity to calculate and remove the compositional spectral effects.

\subsection{Internal Instrument Radiance}

[26] TES spectra contain a systematic background radiance error due to a minor misalignment of the pointing mirror assembly [Christensen et al., 2001]. The feature is a relatively small additive effect $\left(\sim 1.0 \times 10^{-8} \mathrm{~W} \mathrm{~cm}^{-2} \mathrm{sr}^{-1} \mathrm{~cm}^{-1}\right.$ between $\sim 300$ and $1400 \mathrm{~cm}^{-1}$ ), and is less pronounced with increased surface temperature. Because of the low-temperature difference between the planet and detectors during nighttime observations, the rock abundance algorithm is highly sensitive to this spectral contribution. In order to minimize the effect, the spectral response of this additive offset was isolated using space observations and uniformly subtracted from each observation.

\subsection{Atmospheric Contributions}

[27] The effects of atmospheric dust can be minimized by constraining the data as a function of the atmospheric opacity, which has been well characterized using daytime TES observations [Smith et al., 2001]. In addition, modeling the effect of atmospheric contributions to the rock abundance algorithm resulted in a threshold for useful data. With an aerosol dust opacity over $\sim 0.2$, atmospheric scattering and emission cannot be sufficiently removed to produce reliable rock abundance values. This represents conditions seen during the dustiest periods of the Martian year, when large-scale dust storms dominate [Smith et al., 2001; Smith, 2004]. Only data with dust opacity values below this threshold were included in the global data set.

[28] Data collected during the clearest seasons can be corrected to reduce the effect of atmospheric dust. The radiant contributions of aerosols can be modeled with TES-derived opacity, temperature, pressure and spectral shapes. The method for modeling these spectral effects is the same as that used by Smith et al. [2001], and extensively described by Bandfield and Smith [2003]. The nighttime dust opacity is not retrieved with TES observations, however the atmospheric dust content does not change significantly on a diurnal timescale and the daytime opacity can be substituted for nighttime observations at the same latitude, longitude, and $\mathrm{L}_{\mathrm{s}}$. A three-dimensional lookup table with these variables was assembled to find the opacity for each nighttime observation. The temperature/pressure profiles necessary to calculate the aerosol radiance were taken directly from nighttime spectral observations [Conrath et al., 2000]. These correlated measurements were used to calculate the atmospheric attenuation and the radiance contributed from a warm dusty atmosphere with the methods established by Smith et al. [2000].

[29] The spectral shapes of water ice clouds and atmospheric dust were isolated using target transformation and end-member retrieval methods described by Bandfield et al. [2000]. Using these spectral shapes, the radiative transfer equation (equation (1)) is used to calculate the contributions and transmission of energy in a series of layers from the top of the atmosphere down to the surface [Smith et al., 2000]. The lowest layer is added by extrapolating the temperature to the surface pressure [Conrath et al., 2000], which is estimated from elevation and a seasonally adjusted reference pressure based on Viking lander measurements [Tillman et al., 1993]. The radiance of the surface is found by subtracting the integral term (from equation (1)) from the measured radiance, and dividing by the attenuation term $\left(\mathrm{e}^{-\tau \mathrm{o}(\lambda) / \mu}\right)$ [Smith et al., 2000]. This effectively removes the radiance contributed from a warm dusty atmosphere to produce nighttime surface spectra relatively free of atmospheric contributions. 
[30] The presence of nighttime water ice clouds in the data is undetermined, but as they show little thermal contrast from the surface, they are a relatively minor effect [Pearl et al., 2001]. Nighttime clouds are temporally random in occurrence [Smith et al., 2001], and their effects are not observable in the final data set.

\subsection{Surface Emissivity}

[31] The compositional heterogeneity on Mars contributes spectral features that must be isolated in each observation in order to calculate the spectral difference due to surface anisothermality. Daytime TES spectra have previously been deconvolved to retrieve the atmospheric and surface spectral contributions, and produce atmospherically corrected surface emissivity maps [Bandfield, 2002]. These $4 \mathrm{pixel} /$ degree maps were used to determine the emissivity for the location of each nighttime observation and account for the compositionally dependent surface emissivity effects in each channel.

\subsection{Thermal Model}

[32] The model used to predict the nighttime temperature of the rock surface component, and to inversely determine the thermal inertia of the low-temperature component is an updated version of the Viking thermal model [Kieffer et al., 1973], hereto referred to as the KRC model. The atmospheric parameters of the KRC model are fully adjustable, and have been adjusted to approximate the TES thermal model for consistency with the TES thermal inertia data set [Mellon et al., 2000; Jakosky et al., 2000].

[33] The KRC thermal model is used to construct a sixdimensional lookup table which is used to determine the kinetic surface temperature by varying the six model inputs (thermal inertia, time, season, albedo, surface pressure, and latitude). The albedo is retrieved from a 4 pixel/degree map compiled from TES daytime visible bolometer data. Surface pressure is modeled using the measurements from the Viking landers and the location, time, and season are taken from spacecraft ephemeris data. To calculate the temperature of the rock component $\left(\mathrm{T}_{\text {rock }}\right)$, the $1250 \mathrm{~J} \mathrm{~m}^{-2} \mathrm{~K}^{-1} \mathrm{~s}^{-1 / 2}$ thermal inertia value is used to predict the temperature at each observation's time and location. To calculate the thermal inertia corresponding to the fine-temperature component $\left(\mathrm{T}_{\mathrm{fc}}\right)$, it is correlated with the best fitting $\mathrm{KRC}$ model thermal inertia temperature as interpolated from the lookup table.

\subsection{Rock Abundance Algorithm Applied to TES Data}

[34] Equation (7) describes the total radiance as observed by the detector. The application of this equation to single nighttime TES observations requires reducing the number of unknowns using the information about Mars as outlined in the above sections. A flowchart illustrating each data input, model, and algorithm step shows the methodology that was developed to determine rock abundance with the TES data (Figure 4).

[35] In order to minimize the spectral features unrelated to surface anisothermality, the atmospheric and surface emissivity spectral effects were calculated and removed to produce a radiance spectrum that could be described by a mixture of blackbodies $\left(\mathrm{R}_{\mathrm{BB}}[\mathrm{T}, \lambda]\right)$. The modeled additive radiance of the atmosphere as a function of season, latitude,

\section{TES Rock Abundance Algorithm}

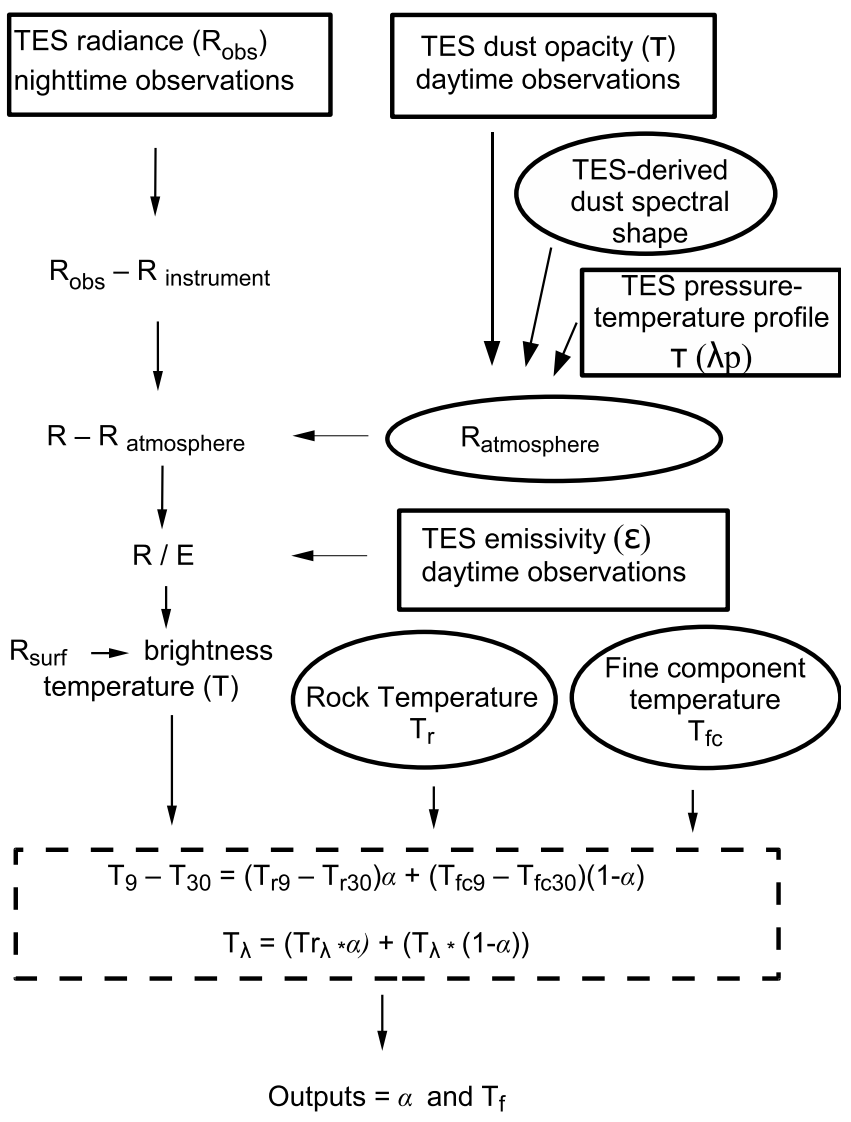

Figure 4. Flowchart for the TES rock abundance algorithm. Solid boxes indicate independent inputs used in the algorithm. Ovals indicate model output that is used as input in further steps, and the dashed box is the iterative fractional brightness temperature calculation. $\mathrm{R}$ is radiance at the sensor, $\mathrm{E}$ is emissivity, and $\alpha$ is the percent rock abundance in a single observation.

and longitude was subtracted from each observation to produce an atmospherically corrected surface radiance spectrum $\left(\mathrm{R}_{\text {surf }}\right)$, and the surface radiance was divided by the surface emissivity $(\varepsilon)$ spectrum for the location of each observation. These atmosphere- and emissivity-corrected radiance spectra were integrated to two- channel brightness temperatures, and used as the inputs for the spectral difference model.

[36] Christensen [1982] assumed an albedo value of 0.10 and inertia of $1260 \mathrm{~J} \mathrm{~m}^{-2} \mathrm{~K}^{-1} \mathrm{~s}^{-1 / 2}$ to calculate the temperature of the rock component, corresponding to a dark solid material such as basalt blocks. We use the same albedo and inertia to calculate the surface rock temperatures. These values correspond to a maximum summertime temperature of $\sim 240 \mathrm{~K}$ at $2.5 \mathrm{H}$ local time. In the TES algorithm we assume that rocky material is composed of dark blocks such as basalts, while lower-inertia material is composed of dustlike material, which ties each temperature component to an assumed albedo [Christensen, 1986a].

[37] With the atmospheric and emissivity parameters accounted for, there are two free parameters in equation (7): 
the temperature of the nonrock component $\left(\mathrm{R}_{\mathrm{BB}}\left[\mathrm{T}_{1}, \lambda\right]\right)$ and the areal fraction of the rock component $(\alpha)$. These two unknowns are determined by solving the equation at two different wavelengths (30 and $9 \mu \mathrm{m}$ ) for each observation, and deriving two new equations using calculated brightness temperature.

[38] The fractional abundance of the rock temperature component is determined from the equation:

$$
T_{9}-T_{30}=\left(T_{9 \text { rock }}-T_{30 \text { rock }}\right) \alpha+\left(T_{9 f c}-T_{30 f c}\right)(1-\alpha)
$$

in which $\mathrm{T}_{9}$ and $\mathrm{T}_{30}$ are the observed brightness temperature in each integrated channel, $\mathrm{T}_{9 \text { rock }}$ and $\mathrm{T}_{30 \text { rock }}$ are the integrated brightness temperatures of a blackbody at the model temperature of rock, $\mathrm{T}_{9 \mathrm{fc}}$ and $\mathrm{T}_{30 \mathrm{fc}}$ are the integrated brightness temperatures of a blackbody at the finecomponent temperature, and $\alpha$ is the rock abundance, or fraction contribution of the rock temperature component. The algorithm assumes the rock temperature as determined by the thermal model, and iteratively calculates the brightness temperature values at each spectral channel, starting with the lowest corresponding temperature of a fine component inertia of unconsolidated dust $\left(24 \mathrm{~J} \mathrm{~m}^{-2} \mathrm{~K}^{-1} \mathrm{~s}^{-1 / 2}\right)$, and increasing until it most closely matches the measured brightness temperature values in both channels. The iterative calculation reconciles the brightness temperature of the model outputs $\left(\mathrm{T}_{\text {rock }}, \mathrm{T}_{\mathrm{fc}}\right)$ with the integrated brightness temperature in each channel $(\mathrm{T})$, described by the equation:

$$
T_{\lambda}=\left(T_{\text {rock } \lambda} \alpha\right)+T_{f c \lambda}(1-\alpha)
$$

A lookup table for every $1 \%$ change in rock abundance and fine component temperatures ranging from $160 \mathrm{~K}$ to $250 \mathrm{~K}$ was compiled. In order to determine the thermal inertia of the fine component, the brightness temperature is treated as a kinetic surface temperature and input back into the inverse of the thermal model. The final model outputs are rock abundance and fine component inertia for each observation. The fractional rock abundance is multiplied by $100 \%$ and expressed as percent rocks in each field of view.

\section{Error Analysis}

\subsection{Random Errors}

[39] There are three sources of uncertainty that affect the final modeled rock abundance value: (1) instrument noise, (2) atmospheric radiance, and (3) surface emissivity. The first is the uncertainty due to instrument noise in the observations, and the latter two are discrepancies that could exist between the modeled values and the actual conditions of the atmosphere or surface. Each of these effects have been previously described in detail. Here we will outline the uncertainties for each source, and provide an analysis of the combination of the uncertainties on the final calculated rock abundance values.

\subsubsection{Instrument Noise}

[40] The noise level of a single TES spectrum is $\sim 2.5 \times$ $10^{-8} \mathrm{~W} \mathrm{~cm} \mathrm{cr}^{-1} \mathrm{~cm}^{-1}$ for wave numbers $\sim 300$ to $1400 \mathrm{~cm}^{-1}$ and increasing to $\sim 6 \times 10^{-8} \mathrm{~W} \mathrm{~cm} \mathrm{sr}^{-1}$ $\mathrm{cm}^{-1}$ at shorter $\left(<250 \mathrm{~cm}^{-1}\right)$ and longer $\left(>1650 \mathrm{~cm}^{-1}\right)$ wave numbers, as determined by prelaunch and in-flight observations [Christensen, 1999]. Under daytime condi- tions, this effect is relatively small, but it increases as the signal decreases with lower surface temperature. Because the rock abundance algorithm uses the relative radiance as a function of wavelength, the effects of the uncertainty as a function of wavelength is nonlinear. The spectral difference uncertainty due to instrument noise is best calculated as a function of surface temperature (Figure 5). The noise equivalent spectral difference ranges from of $\pm 0.1 \mathrm{~K}$ at $240 \mathrm{~K}$ to $\pm 1.15 \mathrm{~K}$ at $160 \mathrm{~K}$.

[41] As a result of the wavelength-dependent spectral uncertainty, the surface temperature as a function of season becomes one of the primary criteria for determining the usefulness of the data. Below an average surface temperature of $\sim 165 \mathrm{~K}$, the short wavelength region becomes dominated by noise, and the spectral anisothermality effects are almost entirely obscured.

\subsubsection{Atmospheric Radiance}

[42] The uncertainties calculated by Smith et al. [2000] for atmospheric opacities retrieved from daytime observations, and by Bandfield [2002], for the modeled atmospheric spectral shapes result in a total opacity uncertainty estimate of about 0.05 for a single observation. A detailed description of these errors is given by Bandfield and Smith [2003].

[43] Uncertainties in the estimates in surface temperature $(0.5 \mathrm{~K})$ and in atmospheric temperatures $(3 \mathrm{~K})$ result in opacity uncertainty of 0.02 for both dust and water ice in daytime observations. When the surface/atmosphere thermal contrast drops below $20 \mathrm{~K}$ (at a surface temperature of $220 \mathrm{~K}$ ), the spectra become too noisy to provide reasonable estimates of water ice opacity. Water ice clouds may be present in nighttime observations, but there is too little thermal contrast between the surface and the atmosphere to obtain reliable aerosol opacities [Pearl et al., 2001]. Nighttime clouds are not corrected for in the model or error calculation, since they are ephemeral on less than a diurnal timescale. In addition, the spectral effects are more likely to subdue high-contrast surface features, rather than induce positive rock values in the data. In addition, the highest opacity of water ice occurs at $825 \mathrm{~cm}^{-1}$, located well outside the spectral channels used here.

[44] We make the assumption that the diurnal atmospheric dust opacity does not change significantly over short timescales. The opacity data was binned in $1^{\circ}$ spatial bins and 100 orbit $\left(4^{\circ} \mathrm{L}_{\mathrm{s}}\right)$ temporal bins. The change in dust opacity for a $4^{\circ} \mathrm{L}_{\mathrm{s}}$ time span between latitudes -60 and 60 , is less than 0.02 for most of the data. During dust storms the atmosphere warmed by as much as $10 \mathrm{~K}$ over 2 days [Conrath et al., 2000; Clancy et al., 2000], but these periods were excluded due to the high overall atmospheric dust opacity. The atmospheric opacity maps used to determine the radiant atmospheric contributions are generated from hundreds of observations per bin, making the uncertainty due to random errors in each observation negligible, although systematic errors are not reduced.

\subsubsection{Surface Emissivity}

[45] The surface emissivity calculation uncertainties are detailed by Bandfield [2002] and provide for a calculable uncertainty in the rock abundance algorithm. The error for emissivity as determined by Christensen et al. [2001] for an average of six detectors and a surface temperature of $280 \mathrm{~K}$ is $<0.0013$ from 300 to $1100 \mathrm{~cm}^{-1}$ and increasing to 0.0035 at $1400 \mathrm{~cm}^{-1}$. The $4 \mathrm{pixel} /$ degree binned emissivity data set 


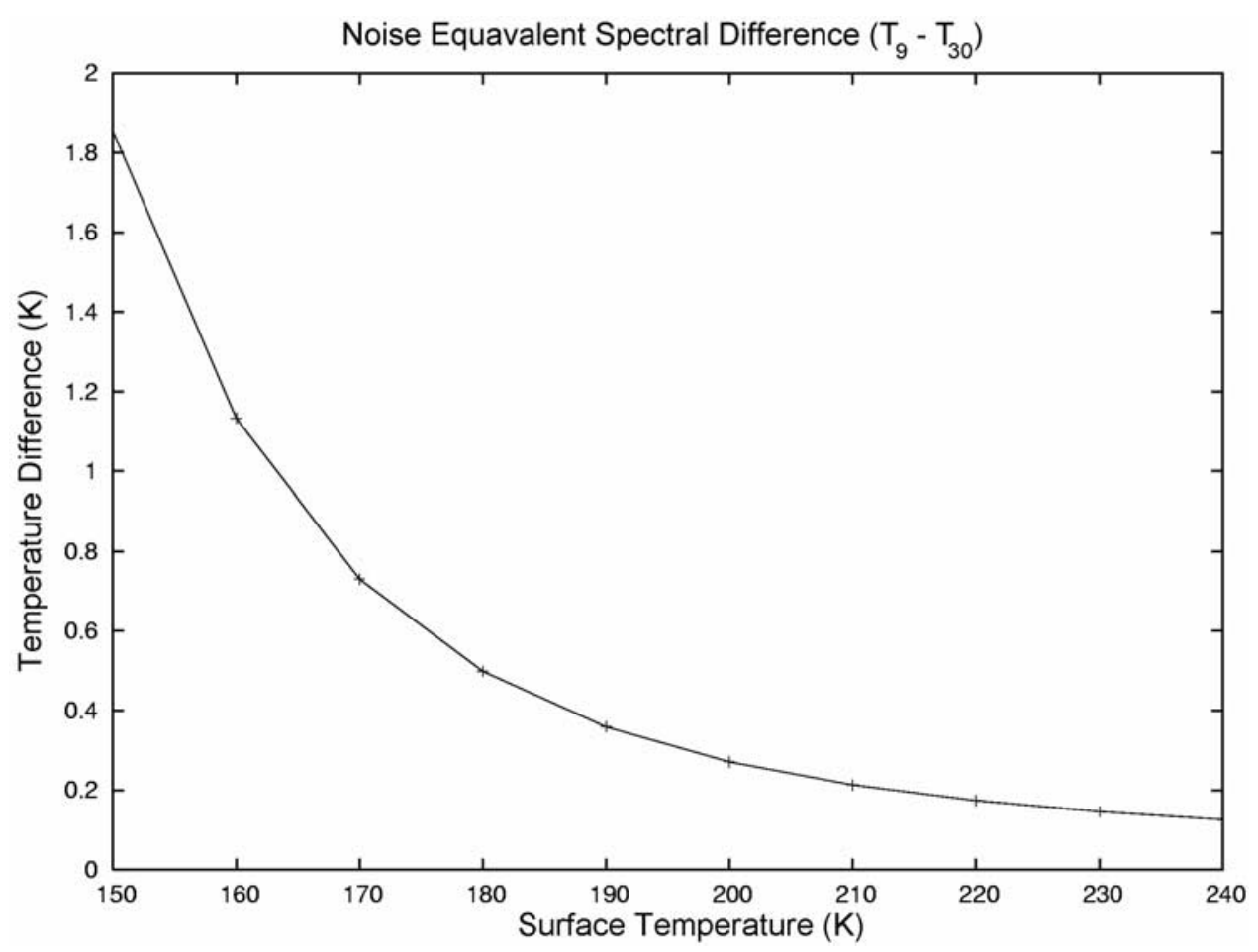

Figure 5. Noise equivalent spectral difference curve. The values are integrated brightness temperature in the 9 and $30 \mu \mathrm{m}$ channels. Data used in this study require a spectral difference unknown of less than $\pm 1 \mathrm{~K}$, corresponding to a surface temperature $>165 \mathrm{~K}$.

used here includes large numbers of spectra in the averages as well as multiple orbit tracks which systematically reduce the noise induced with calibration, and result in significantly lower-emissivity errors, making it insignificant compared to the possible subpixel emissivity variation on any surface.

\subsubsection{Summary}

[46] The total calculated uncertainty in a single TES observation is almost entirely dependent upon the average temperature of the observation due to season and latitude, and the magnitude of the spectral difference between the 9 and $30 \mu \mathrm{m}$ channels. For a high-temperature surface observation $(>200 \mathrm{~K})$, the combined effects of instrument noise, surface emissivity uncertainties, and atmospheric radiance result in less than a $2 \%$ uncertainty in rock abundance values. With surface temperatures below $170 \mathrm{~K}$ and low rock abundance $(<10 \%)$, the uncertainties can increase to $40 \%$ of the rock value.

[47] The greater the spectral contrast, the lower the overall error. Thus a combination of data characteristics can be used to determine the uncertainty for any single observation. The best case is a low fine-component inertia $(<100)$, a high rock abundance $(30 \%)$, and high-temperature observation $(>200 \mathrm{~K})$. The worst case is a moderate finecomponent inertia $(>300)$, a low rock abundance $(<10 \%)$, and a low-temperature season observation. Assuming a surfaces with a low fine-component inertia and summer observation, the uncertainty is $\pm 5 \%$ in the $0-10 \%$ rock abundance range, decreasing to $\pm 1 \%$ at $50 \%$ rocks.

\subsection{Systematic Error}

[48] A model parameter that can have an effect on the derived rock abundance is the albedo of the model rock component. The albedo has the least effect on component temperature during predawn observations, but the effect becomes significant at the highest thermal inertias. Thus the largest effect assumed albedo can have is for the nighttime rock temperatures. The albedo of the fine component isn't significant in calculating the rock abundance, and has a relatively small effect on the fine component inertia.

[49] Observations made at landing sites have shown that in some regions on Mars, rocks are likely to have an albedo greater than 0.1. Most recently, data from the Pancam imagers on board the 2003 Mars Exploration Rovers have been used to derive calibrated albedo values for surfaces observed by the landers. At the MER-A landing site the derived albedo values for gray rock surfaces were on the order of 0.10 to 0.15 , but many rocks displayed moderate to high albedo surfaces $(0.20-0.30)$ due to dust covering the surface [Bell et al., 2004]. This variability suggests that our albedo assumption is reasonable for dust-free rocks, but in landing site observations no completely dust-free rocks have been observed.

[50] Rocks can be coated or dust-covered, and thus absorb less total solar energy during the day than the modeled rock component used in this study. In extreme cases, the modeled nighttime rock temperature can be as much as $10 \mathrm{~K}$ lower with an albedo of 0.3 . No lander has been sent to any regions that are representative of the highest albedo surfaces on the planet, and no data exists for the rock and soil albedos in these regions. A variable rock albedo assumption is not included in the uncertainty calculation, as the characteristics of rocks on Mars are only known for a limited portion of the planet. In comparison to 


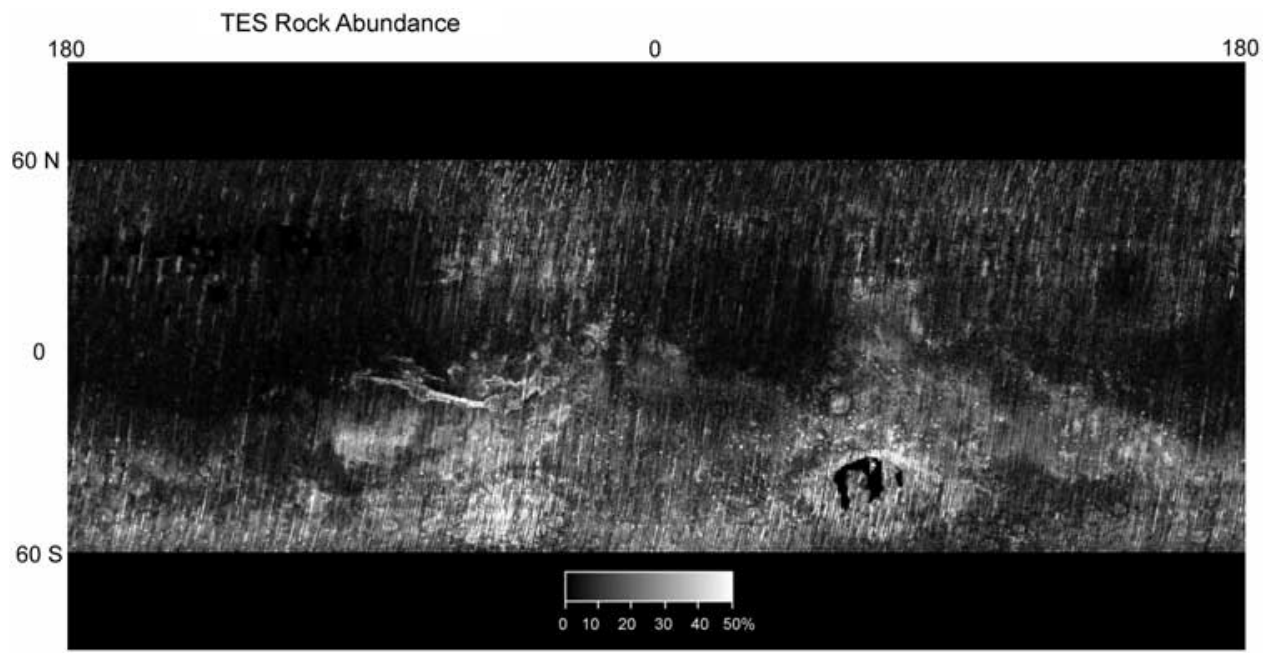

Figure 6. TES 8 pixel/degree global rock abundance map. TES coverage is not extended past $60^{\circ}$ latitude due to seasonal frost and atmospheric conditions. Black pixels in Hellas Basin and Olympus Mons indicate that there is no useful data for those surfaces.

the assumed albedo method used here, moderate albedo differences in rocks will cause less than a 5\% increase in the rock values even for the brightest surfaces.

\section{Results}

\subsection{Global Data Sets}

[51] Over 4.9 million observations were used to generate the global rock abundance data set (Figure 6). The 8 pixel/ degree map has a total coverage of $\sim 45 \%$ of the planet between latitudes -60 and 60 . Data gores in the map were filled by using the surrounding pixels inversely weighted as a function of distance. Surfaces that have extremely low nighttime surface temperatures or high dust opacities (e.g., Olympus Mons, Hellas basin) and thus do not have good systematic data coverage were left unfilled. A map of the model-derived fine-component inertia was also compiled at the same resolution (Figure 7). While this data set is part of the calculation for determining rock abundance, it can be treated as an independent characteristic. Thus it provides additional information for interpreting the nature of the surface materials. The resolution of the binned maps has an effect on the shape of global frequency distribution curves due to the geometry of the observations. Because the surface was observed by TES at $\sim 3 \mathrm{~km}$ resolution with a significant gap in longitude between orbit tracks (often twice the width of a TES track), each bin is randomly sampled over the surface area. This sampling causes an effect that can be seen in the global histogram as a function of resolution (Figure 8). At low bin resolutions, the areas displaying extreme high and low values get averaged to produce bins with more median values. With higher bin resolution, the extreme values are observed with a higher occurrence, due to the statistical nature of smaller-area observations. While each histogram displays a legitimate distribution of global values, this geometry effect should be

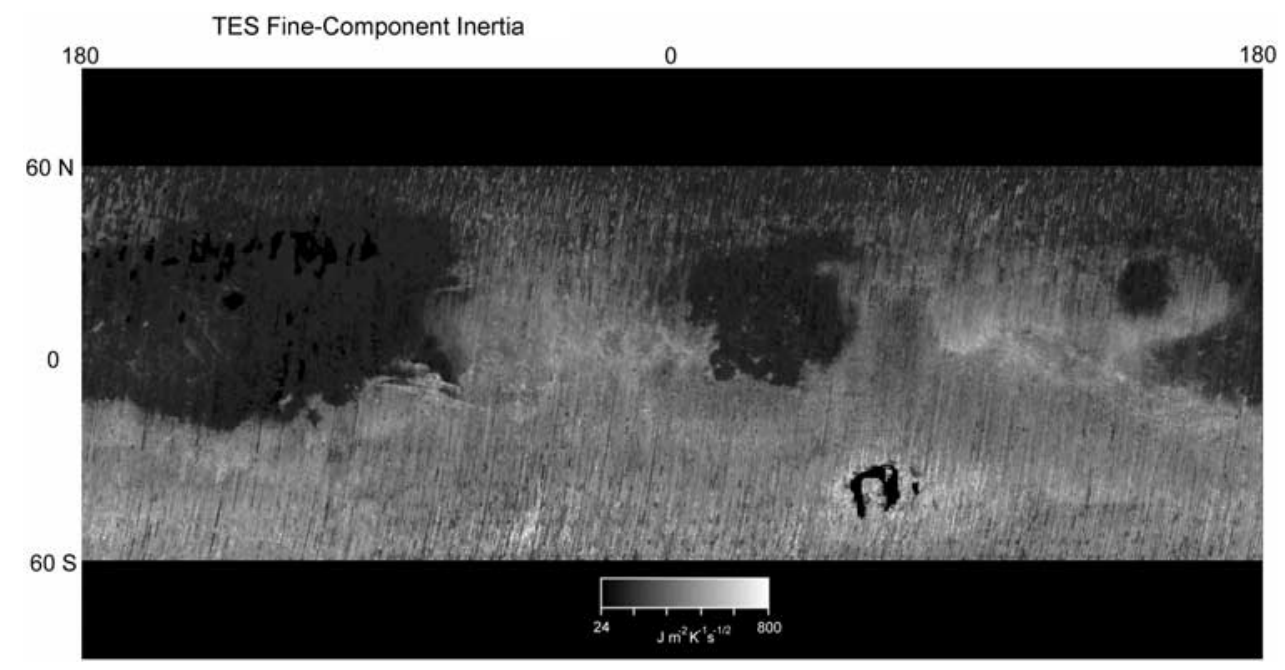

Figure 7. TES 8 pixel/degree global fine-component inertia map. Black pixels in Hellas and Tharsis indicate that there is no useful data for those surfaces. 


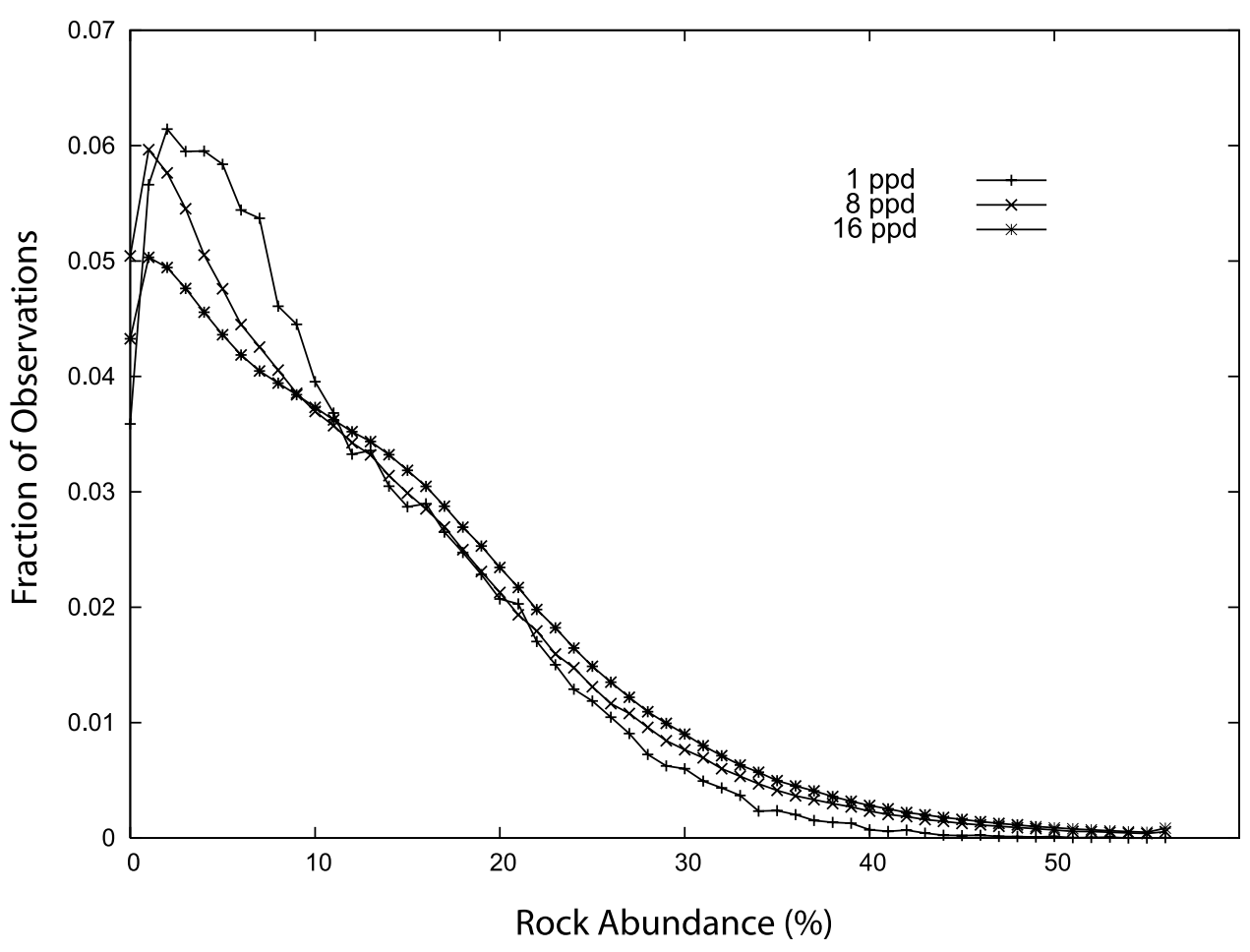

Figure 8. Comparison of histograms from global maps at 1, 8, and 16 ppd. All histograms were generated with the 4.9 million observation data set and binned at different resolutions. The difference between the histograms is a function of the geometry of the $3 \times 3 \mathrm{~km}$ observations on a simple cylindrical projection.

taken into account when comparing the rock abundance map to data sets at other resolution.

[52] In the 8 pixel/degree data set, there is an average of four observations per bin, and the modal maximum occurs at two observations per bin. Thus binning at 8 pixel/degree has two major effects: it effectively reduces the random noise by averaging several values together, and/or it samples more of the total surface area observed in a bin. This second effect produces average rock abundance values in a bin that might have more extreme minimum and maximum values. The histogram of observed 8 pixel/degree binned rock abundance data set has a modal maximum at $2-3 \%$ rocks, with an average of $12 \%$ rocks globally. At this resolution, less than $1 \%$ of the planet has rock abundances over $50 \%$, and only $7.4 \%$ of the observed planet has greater than $30 \%$ rocks. The global fine-component inertia average is $240 \mathrm{~J} \mathrm{~m}^{-2} \mathrm{~K}^{-1} \mathrm{~s}^{1 / 2}$, with a distinct modal peak at $111 \mathrm{~J} \mathrm{~m}^{-2} \mathrm{~K}^{-1} \mathrm{~s}^{-1 / 2}$ and diffuse peak at $310 \mathrm{~J} \mathrm{~m}^{-2} \mathrm{~K}^{-1} \mathrm{~s}^{-1 / 2}$.

\subsection{Data Correlation and Validation}

\subsubsection{IRTM Rock Abundance}

[53] The TES results are presented in a format similar to the Viking IRTM (Figure 9), but a direct comparison is difficult considering the differences in spatial resolution and sampling of observations as described in section 6.1. (Figure 10). When TES data are averaged into $1^{\circ}$ bins, a significant fraction of the area included in the bin is not observed. Thus binned values are randomly biased toward the portions of the bin that are observed. There is also a systematic bias away from extremely low-temperature surfaces $(<165 \mathrm{~K})$, since surface temperature is used as a data

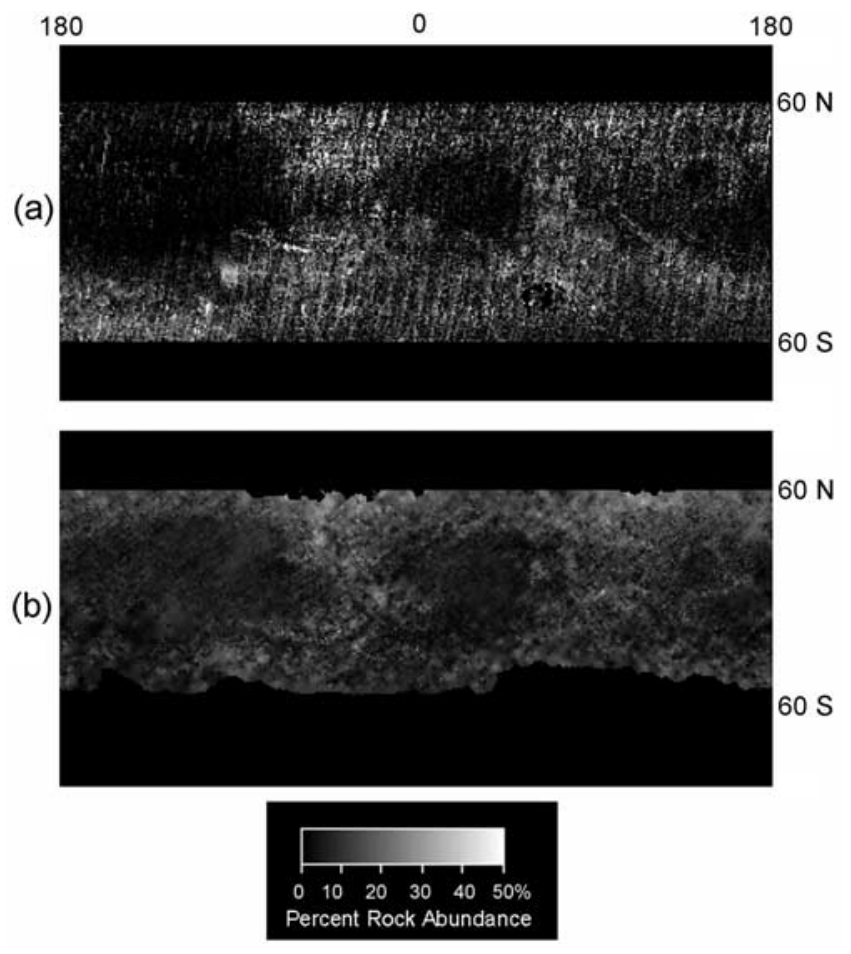

Figure 9. Comparison of (a) TES rock abundance map convolved to $1 \mathrm{pixel} /$ degree and (b) IRTM rock abundance map. 


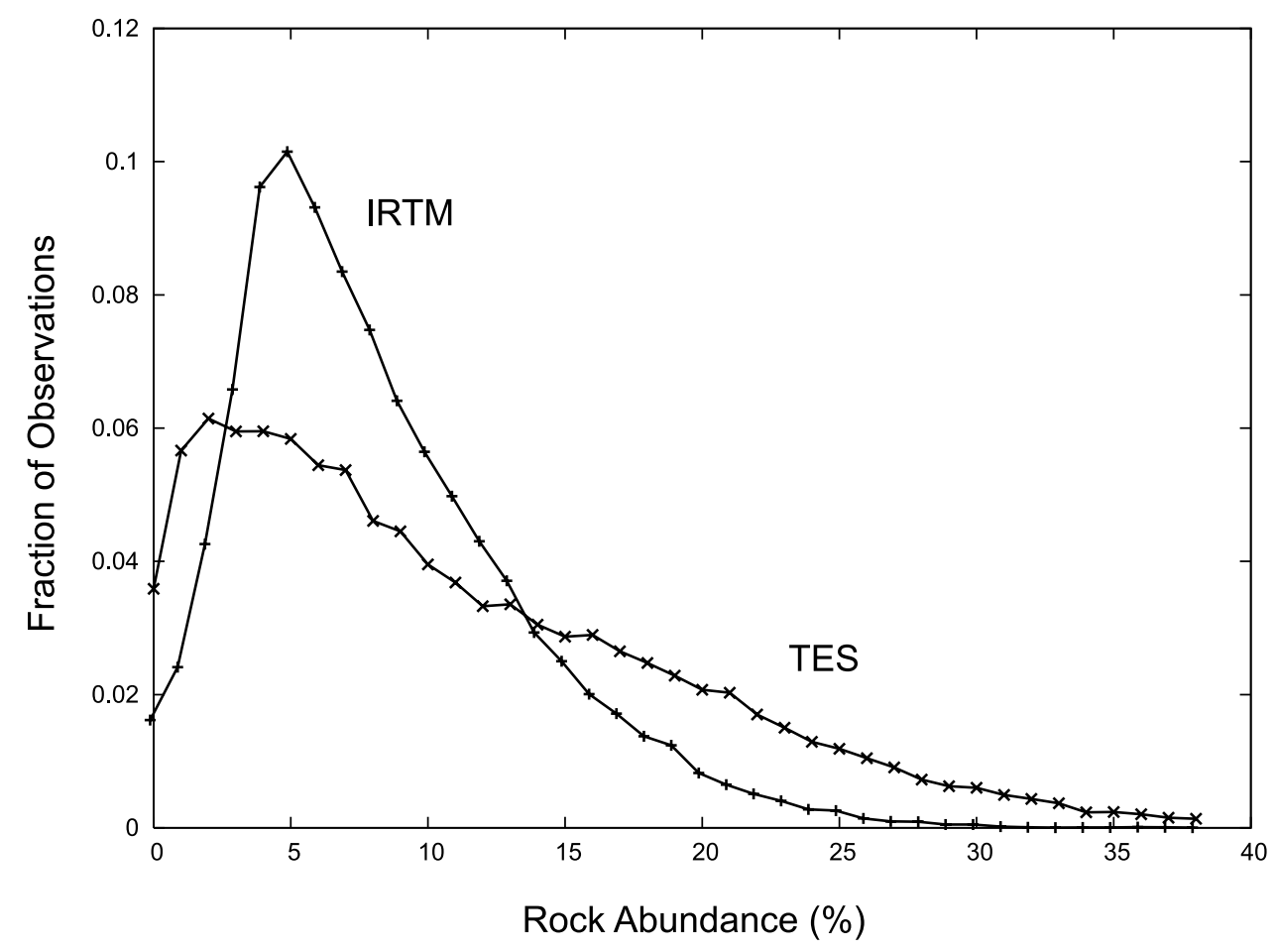

Figure 10. Comparison of histograms from the TES and IRTM data sets. Both are generated from data binned at 1 pixel/degree. Histograms are normalized by dividing the number of bins in each rock abundance value by the total number of bins in the data set. The differences in histogram shape can be attributed to the higher resolution of TES observations.

constraint. Since the IRTM data has a $30 \times 30 \mathrm{~km}$ footprint, and a bin resolution approximately double that size, the IRTM global map was compiled with observations that not only observed the majority of each bin, but that have multiple observations per bin.

[54] Given the data set characteristics, the agreement between TES and IRTM contains few surprises. The major rocky regions match in both maps, and the relative distribution of rocks agree on the global scale. The higher occurrences of both rocky $(>20 \%)$ and rockless surfaces $(0 \%)$ in TES data was expected, considering the higher resolution of the TES data. This resolution is likely to observe surfaces that formed from a single geologic process, such as an impact, fluvial erosion, or volcanic flow, as compared to IRTM which was more likely to observe multiple surface types in a single observation. As a result, we are able to map rock and inertia values that can be used to distinguish specific units and surfaces possibly resulting from a single or uniform set of processes.

\subsubsection{Fine-Component Inertia}

[55] The fine-component inertia can be interpreted similarly to TES bulk thermal inertia [Jakosky et al., 2000; Mellon et al., 2000]. It is a property that depends on the particle size and degree of induration of all the materials in the field of view excluding rock. Any combination of finecomponent inertia and rock abundance are possible. A surface with a high rock abundance value and a low finecomponent inertia can be interpreted as a checkerboard mixture of rock and dust, since very low inertias (24$150 \mathrm{~J} \mathrm{~m}^{-2} \mathrm{~K}^{-1} \mathrm{~s}^{-1 / 2}$ ) are interpreted to result from the accumulation of atmospheric dust [Pollack et al., 1979;
Christensen, 1986b]. A high fine-component inertia can be the result of a number of conditions on the surface, including the presence of large grain size material such as sand [Presley and Christensen, 1997], gravel, or a finegrained material that has developed a duricrust [Jakosky and Christensen, 1986].

[56] At a global scale, the Martian surface displays a complex relationship between rock abundance and finecomponent inertia (Figure 11a). For most of the planet, regions displaying high rock abundance typically have a moderate to high fine-component inertia, while rockless surfaces are composed of nearly uniform low-inertia materials, typically displaying fine-component inertias below $150 \mathrm{~J} \mathrm{~m}^{-2} \mathrm{~K}^{-1} \mathrm{~s}^{1 / 2}$. This distribution of rock and inertia values suggests that rocky surfaces are usually made up of a mixture of moderate to high-inertia materials, while the lowest fine-component inertia surfaces are relatively homogeneous.

[57] The fine-component inertia concentration at $<100 \mathrm{~J}$ $\mathrm{m}^{-2} \mathrm{~K}^{-1} \mathrm{~s}^{1 / 2}$ (Figure 11a) is a significant portion of the planet, and represents the three low-inertia regions, the Tharsis Highlands, Elysium Mons, and Arabia Planitia. These are homogeneous surfaces, where most likely a uniform depositional process controlled the distribution of materials. The rest of the planet is more diffusely represented on the plot, indicating that more than one process may have been at work.

[58] The concentration around a fine component inertia of $\sim 300 \mathrm{~J} \mathrm{~m}^{-2} \mathrm{~K}^{-1} \mathrm{~s}^{1 / 2}$ represents the second unit in the classic bimodal distribution of thermal inertia on the planet [Kieffer et al., 1977]. While the correlation between rock 

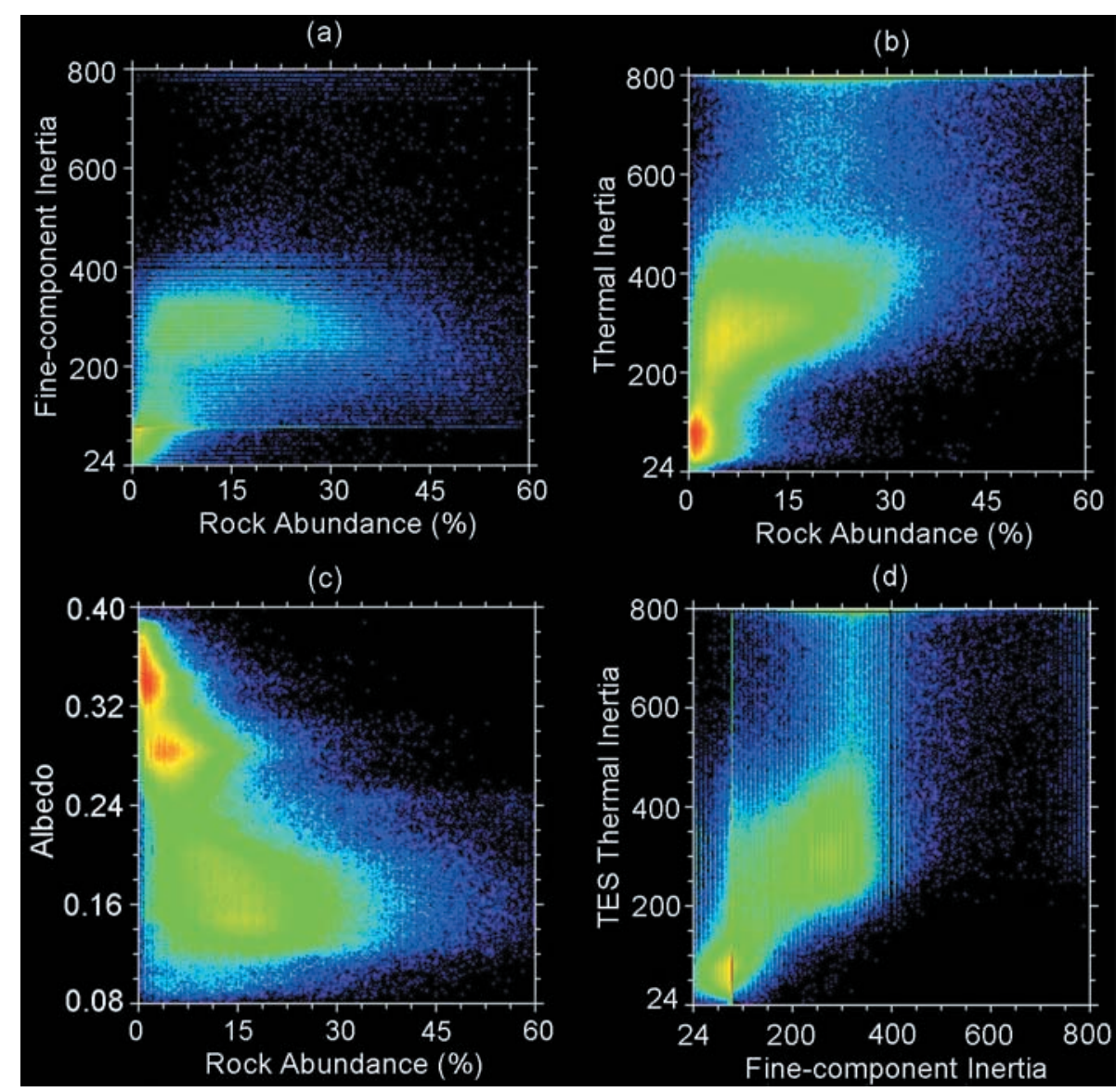

Figure 11. Scatterplots of global TES data sets. All data sets are 8 pixel/degree resolution, from -60 to 60 latitudes. Fine-component inertia and thermal inertia are in units of $\mathrm{J} \mathrm{m}^{-2} \mathrm{~K}^{-1} \mathrm{~s}^{-1 / 2}$. (a) Finecomponent inertia versus rock abundance, (b) TES bulk thermal inertia versus rock abundance, (c) TES bolometric albedo versus rock abundance, and (d) TES bulk inertia versus fine-component inertia.

and fine-component inertia is not as focused, this may indicate that there is a global process that preferentially produces materials in the $300 \mathrm{~J} \mathrm{~m}^{-2} \mathrm{~K}^{-1} \mathrm{~s}^{1 / 2}$ range. This inertia value corresponds to aeolian sand with an average particle size of 800-900 $\mu \mathrm{m}$ [Presley and Christensen, 1997]. A second possibility is that a common process is indurating fine dust deposits into a duricrust with an inertia of 300 [Jakosky and Christensen, 1986]. The third interpretation is that the concentration of fine-component inertias around $300 \mathrm{~J} \mathrm{~m}^{-2} \mathrm{~K}^{-1} \mathrm{~s}^{1 / 2}$ simply represents an average peak inertia resulting from a number of independent surface processes.

[59] While rock abundance may be dependent on the finecomponent inertia, the inverse is not necessarily the case. The presence of two distinct concentrations of values in the scatterplot indicates that fine-component inertia is not highly dependent upon rock abundance. Either the processes exposing rocks and generating high fine-component inertias are unrelated, or both are the result of a single process, and rock exposure represents an extreme case.

\subsubsection{Thermal Inertia}

[60] TES bulk thermal inertia is the modeled value that represents the average temperature of all materials in the field of view. Thus any single thermal inertia value can be a combination of a mixture of high- and low-inertia materials, or a uniform grain size covering the entire surface. A bulk thermal inertia of $300 \mathrm{~J} \mathrm{~m}^{-2} \mathrm{~K}^{-1} \mathrm{~s}^{1 / 2}$ can be a surface composed entirely of $800-900$ micron grains, or a mixture of gravel with an inertia of $1000 \mathrm{~J} \mathrm{~m}^{-2} \mathrm{~K}^{-1} \mathrm{~s}^{1 / 2}$ and dust with an inertia $<150 \mathrm{~J} \mathrm{~m}^{-2} \mathrm{~K}^{-1} \mathrm{~s}^{1 / 2}$, or a duricrust with an average inertia of $\sim 300 \mathrm{~J} \mathrm{~m}^{-2} \mathrm{~K}^{-1} \mathrm{~s}^{1 / 2}$. Thermal inertia is derived differently from rock abundance and fine-component inertia, thus the differences in the data sets are real physical information (Figure 11b). While data appropriate for calculating rock abundance values have a relatively limited coverage, TES bulk thermal inertia have been collected for every bin at multiple seasons.

[61] Surfaces with bulk thermal inertias below $200 \mathrm{~J} \mathrm{~m}^{-2}$ $\mathrm{K}^{-1} \mathrm{~s}^{-1 / 2}$ almost exclusively have low rock values, and is a result of the large-scale low-inertia regions on the planet. Between 200 and $600 \mathrm{~J} \mathrm{~m}^{-2} \mathrm{~K}^{-1} \mathrm{~s}^{-1 / 2}$ there is a wide range of fine-component inertia values, with higher average rock values. Above $600 \mathrm{~J} \mathrm{~m}^{-2} \mathrm{~K}^{-1} \mathrm{~s}^{-1 / 2}$, the rock abundance typically is greater than $10 \%$, indicating that most of the highest thermal inertia surfaces have a relatively high rock component.

\subsubsection{Albedo}

[62] The albedo data set used here was collected using the TES visible/near-infrared bolometer [Christensen et al., 2001]. The value is the ratio of reflected energy to solar incident energy, and is assumed to be Lambertian. This is a measurement that is controlled by the color, roughness, 
(a)

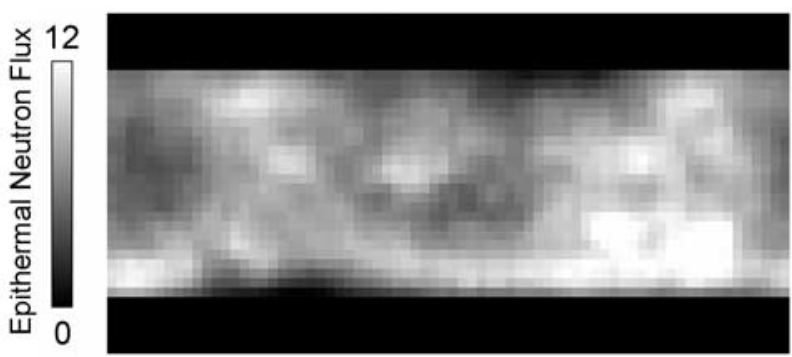

(b)

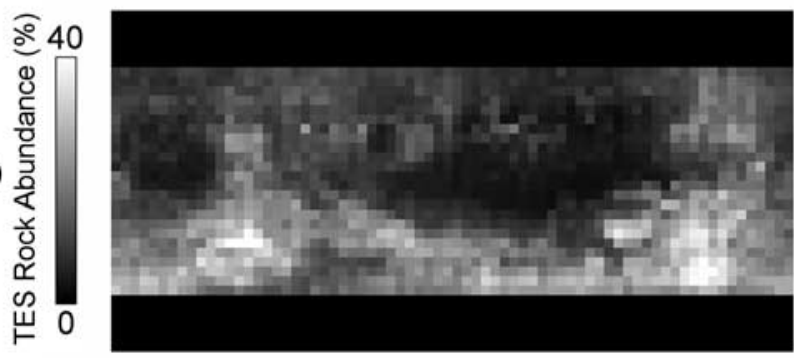

(c)

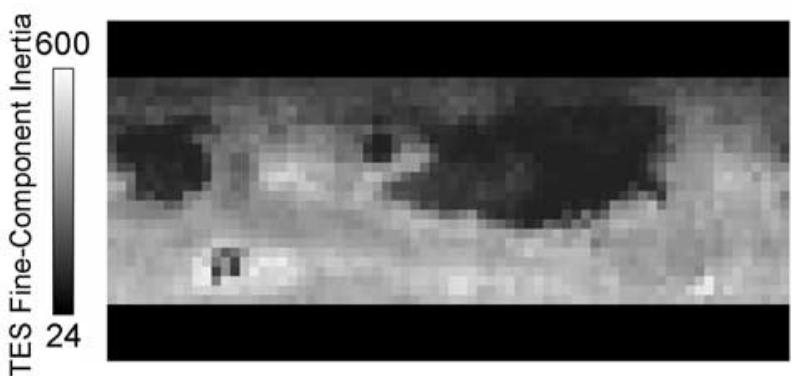

Figure 12. Ten degree/pixel data sets for comparison to GRS results, limited to -60 to 60 latitudes. (a) Epithermal neutron flux from the HEND experiment. (b) TES rock abundance. (c) TES fine-component inertia.

slope, frost, and particle size of the materials in the upper few tens of microns of the surface [de Vaucouleurs, 1967; Kieffer et al., 1977]. Bolometric observations are collected at the same $3 \times 3 \mathrm{~km}$ resolution as other TES observations, and were binned using the same method, resulting in a map where values are an average of all the observations in each spatial bin. The 8 pixel/degree data set was assembled using observations from the clearest seasons during the mission, including mapping phase observations for more than two years from the start of the mission.

[63] Comparison of rock abundance and bolometric albedo shows that there is an inverse relationship between rockiness and reflectivity (Figure 11c). As part of the rock abundance algorithm, we assume that rocks are the lowest albedo materials on the surface, corresponding to dark basaltic blocks with an albedo of 0.1 [Christensen, 1982]. The model parameter for the fine-component is at the other end of the albedo range of the planet, with an assumed value of 0.3. While component albedo is an assumption in the thermal model, the bolometric observations provide an indication that this assumption holds true for the majority of the planet.

[64] There are two sharp modes and a diffuse concentration in the rock abundance/albedo plot. The highest albedo concentration displays very low rock abundance, with most surfaces below $5 \%$ rocks with albedos above 0.34 . This corresponds to the classic low-inertia regions. The second concentration of values is an intermediate surface with low to moderate rock abundances. The diffuse modal peak of rocky surfaces with low albedo $(\sim 0.15)$ centered at $\sim 12 \%$ rocks indicates that these surfaces are not homogeneous. The wide range in both values most likely indicates that rocky surfaces can have varying amounts of dust that has been deposited as a result of global dust storms.

\subsubsection{Fine-Component and Thermal Inertia}

[65] The correlation of TES thermal inertia and finecomponent inertia suggests that most of Mars' bulk inertia is controlled by the fine-component inertia (Figure 11d), with rock abundance contributing to bulk inertia values primarily in areas with high fine-component inertias. The most interesting feature is the distinct concentration of values around $300 \mathrm{~J} \mathrm{~m}^{-2} \mathrm{~K}^{-1} \mathrm{~s}^{-1 / 2}$ in both fine-component and bulk thermal inertia. The high correlation of surfaces with the same fine component and thermal inertia provides evidence that there may be a process concentrating inertia values in that range.

[66] Christensen (1986a) concluded that the fine component inertia controls the thermal inertia for the majority of the planet, but we find that this is not applicable for the highest-inertia units at TES resolution. Instead, a high finecomponent can generate surfaces up to bulk inertias in the $300 \mathrm{~J} \mathrm{~m}^{-2} \mathrm{~K}^{-1} \mathrm{~s}^{-1 / 2}$ range, and rocks are required to increase the inertia above that level. Mars can thus be modeled with three primary thermophysical components: dust $\left(<150 \mathrm{~J} \mathrm{~m}^{-2} \mathrm{~K}^{-1} \mathrm{~s}^{-1 / 2}\right)$, a moderate inertia component $\left(\sim 300 \mathrm{~J} \mathrm{~m}^{-2} \mathrm{~K}^{-1} \mathrm{~s}^{-1 / 2}\right)$, and rocks $\left(>1250 \mathrm{~J} \mathrm{~m}^{-2} \mathrm{~K}^{-1} \mathrm{~s}^{-1 / 2}\right)$. Combinations of these three components can make the full continuum of surfaces observed in bulk inertia values.

\subsubsection{Gamma Ray Spectrometer}

[67] Observations from the Mars Odyssey gamma ray spectrometer (GRS) have been used to map the distribution of hydrogen in the Martian regolith, which is interpreted to be the presence of subsurface ice and hydrated soils in the upper meter of the surface [Boynton et al., 2002; Feldman et al., 2002; Mitrofanov et al., 2002]. The epithermal neutron flux, which indicates the presence of subsurface water, is most correlated with latitude. The southern latitudes below $\sim 50^{\circ}$ have the lowest flux counts, and as a result, the highest water abundance. The most water-rich areas on the planet are not easily mapped with rock abundance data, since they are very high latitude, but the rest of the planet has interesting correlations with thermophysical properties. Keller et al. [2003] found a weak correlation between GRS hydrogen abundance and IRTM-derived thermal inertia, albedo, and rock abundance. The geographic distribution of ground ice in the Martian soil was found to depend on the latitude, thermophysical properties of the soil, and atmospheric water vapor density [Mellon et al., 2004] indicating that water is present in the hydrous minerals within the highly altered soil, and distinctly absent from rocky regions [Keller et al., 2003].

[68] We compare the epithermal neutron flux from GRS experiment with TES rock abundance (Figure 12) at the highest resolution of the GRS data (8 degree/pixel), and find a similar result as Keller et al. [2003], although with a higher correlation with epithermal neutron flux (Figure 13). High rock abundances are present in areas with little 

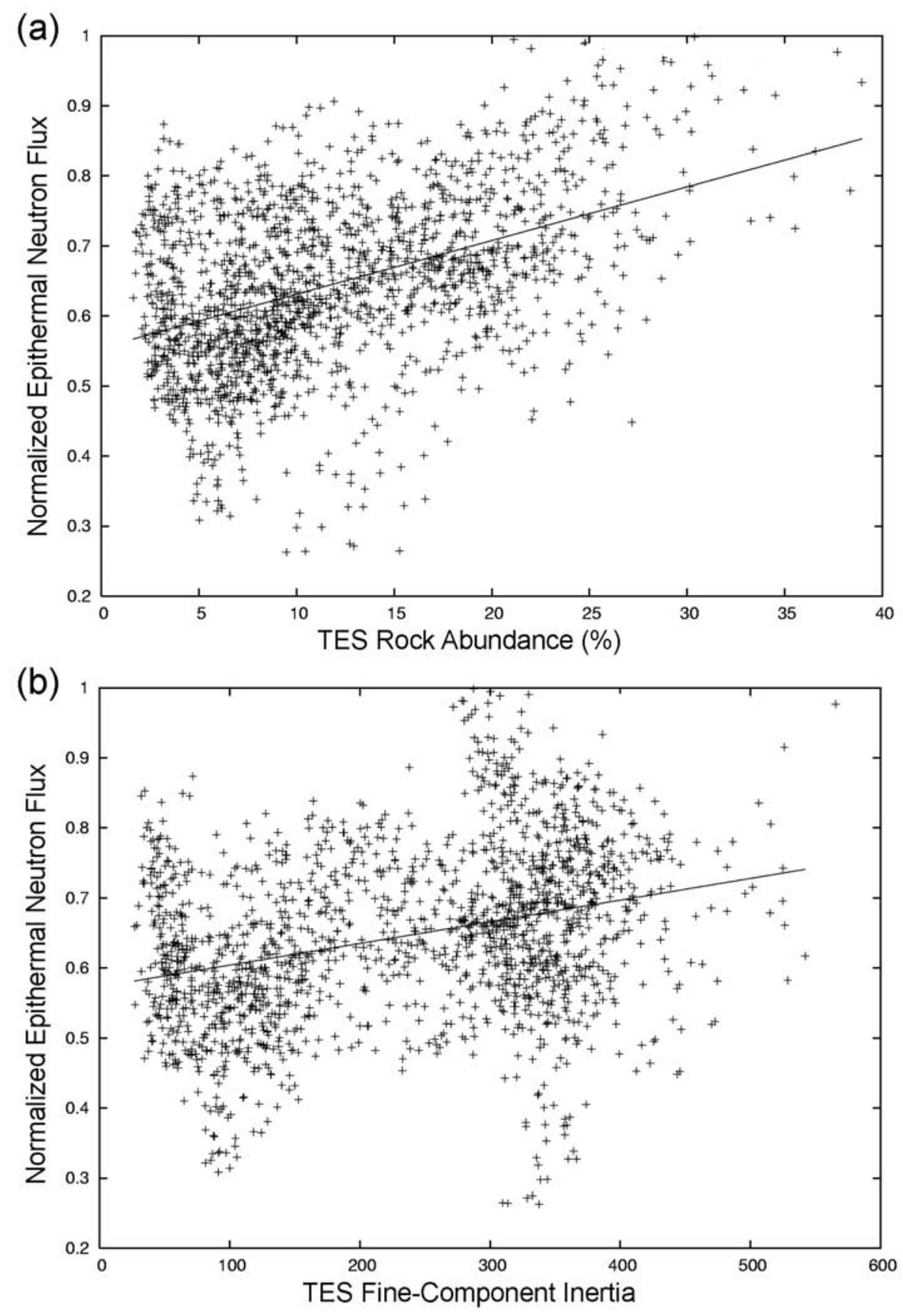

Figure 13. Plots of correlation between (a) TES rock abundance and (b) fine-component inertia with GRS epithermal neutron flux at $8^{\circ}$ bin resolution.

subsurface water, indicating a lack of soil alteration on rocky surfaces. We also find a weaker correlation between flux and fine-component inertia, indicating that the finecomponent inertia is an independent surface characteristic, and not as well controlled by the presence of water in the regolith.

\subsubsection{Landing Sites}

[69] The five visited Mars landing sites are the only points of reference for directly relating remotely observed rock abundance to in situ information about the surface. For each site, all available TES data were compiled and used for mapping. Normally, spacecraft operations including solar panel and high-gain antenna motor operation can induce spectral noise in TES observations. While we used these conditions to constrain noisy data in the global data set, they were ignored in selecting the data for mapping the landing sites. In order to reduce overall error, the noisiest tracks were identified and removed manually. As a result, the landing site maps contain more data than is available for these areas in the global data set, providing better spatial coverage, although with potentially a greater uncertainty in any given pixel. This results in excellent data coverage for a 
Table 1. Rock Abundance Values From TES, IRTM, and Observations Made From the Lander Images ${ }^{\mathrm{a}}$

\begin{tabular}{llcc}
\hline Landing Site & $\begin{array}{c}\text { TES Rock } \\
\text { Abundance }\end{array}$ & $\begin{array}{c}\text { IRTM Rock } \\
\text { Abundance }\end{array}$ & $\begin{array}{c}\text { Lander } \\
\text { Observations }\end{array}$ \\
\hline Viking 1 & $8 \pm 5$ & 16 & 16 \\
Viking 2 & $13 \pm 4$ & 17 & 16 \\
Pathfinder & $12 \pm 4$ & 19 & 19 \\
Spirit & $11 \pm 4$ & 8 & 7 \\
Opportunity & NA $(9 \pm 6)$ & 5 & $\leq 5$ \\
\hline
\end{tabular}

a IRTM data are calculated from Christensen [1986a] and selected by Golombek et al. [2003b]. Viking 1 and 2 rock counts were made by Moore and Keller [1989, 1990]. Pathfinder lander rock values are from Golombek et al. [1997]. At the MER-A Spirit landing site, Golombek et al. [2005, 2006] calculate rock abundances that vary from 5 to $30 \%$, and adjusting the overall plains rock abundance to the average thermal inertia results in an average of $7 \%$. TES observations are not available for the MER-B Opportunity site due to a regular equatorial atmospheric observation.

small area, but is impractical for the millions of observations in the global data set.

[70] The maps of the landing site regions show the highresolution projected footprint of the TES pixels represented by the individual colored squares, and superimposed on Viking photomosaics for context. Comparisons are made between binned 8 pixel/degree TES rock abundance and 1 pixel/degree IRTM values presented by Christensen [1986a] and selected by Golombek et al. [2003b]. Table 1 includes the values from IRTM and TES, and best estimate rock counts performed using visible lander images [Moore et al., 1979; Moore and Keller, 1990, 1991; Golombek et al., 1997; Grant et al., 2004; Golombek et al., 2005; Crumpler et al., 2005]. While three of the five sites are observed directly with TES, Viking Lander 1 (VL1) and Mars Exploration Rover-B (MER-B) are not. The closest TES observation for the VL1 is $\sim 3 \mathrm{~km}$ from the site. The value for VL1 has been interpolated from surrounding pixels to provide a rough estimate of surface rock abundance, although the actual site has not been observed. For MER-B, the closest observations are $>30 \mathrm{~km}$ away, and do not provide a reliable estimate of the rock abundance at the landing site.

[71] The Mars Exploration Rover-A (MER-A) landing site in Gusev crater was targeted to search for evidence of environmental conditions necessary for life [Squyres et al., 2003]. The sediments in the landing site were predicted to be fluvial or lacustrine, related to Ma'adim Vallis and the crater-filling event [Cabrol et al., 1996]. What was observed by the rover is flat, rocky terrain, with rock size distributions and materials dominated by impact events, with some features resulting from recent aeolian processes [Grant et al., 2004; Golombek et al., 2006]. Detailed analyses of rock populations and physical characteristics of surface materials were made at the landing site and along the rover traverse [Crumpler et al., 2005; Golombek et al., 2005; Golombek et al., 2006]. These analyses provide a more spatially significant analysis of the physical properties, allowing a more effective comparison to the TES data. The observations resulted in rock abundances between 5 and $30 \%$, and an adjusted average of $7 \%$ for the cratered plains [Golombek et al., 2005, 2006]. From the best estimate projection, most of the Spirit's traverse occurred within a single TES detector observation, which displays a calculated rock abundance of $\sim 11 \pm 4 \%$, and multiple observations were not found of this area. The Columbia Hills were likely observed by the next TES detector to the east in the orbit track, and display a slightly lower rock abundance of $9 \pm 5 \%$.

[72] Regionally, TES data display surfaces with rock abundances approaching 30\% in the lower-albedo surfaces in the region (Figure 14). The TES value of $11 \pm 4 \%$ compared to $8 \%$ from IRTM suggests that the higher spatial resolution of the TES data is able to distinguish the smaller kilometer-scale surface units and variations in materials observed within the crater. Because these variations are well correlated with the albedo variations seen in Gusev, it is likely that the rock distribution is a function of the more recent processes such as aeolian dust deposition or soil formation, rather than the original impact events.

[73] The MER-B lander was targeted for Meridiani Planum due in part to the unique mineralogic unit identified in the region [Christensen et al., 2000], but also because of the evidence for homogeneous surface materials, and the likelihood for a safe landing site [Golombek et al., 2003b]. Because of the latitude of Meridiani Planum, the TES coverage is some of the most complete, yet because of an atmospheric observation that TES performs at $0^{\circ}$ latitude on every orbit, the landing site was not directly observed. The map of TES observations shows that the majority of the Meridiani hematite unit has very low rock abundance, while some surfaces located outside the layered unit are rocky (Figure 15). Rover images show a terrain that is nearly

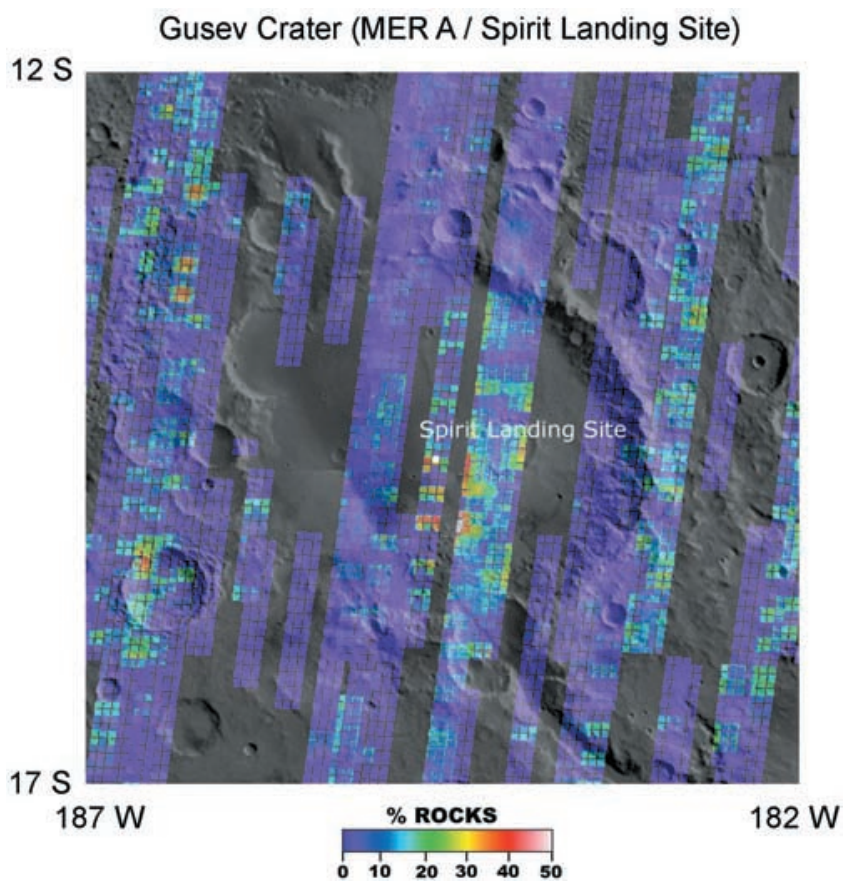

Figure 14. Rock abundance in the Spirit/MER-A landing site region. TES observations are represented by the $3 \times$ $3 \mathrm{~km}$ footprint of each detector draped over Viking photomosaics for context. Map is $5^{\circ} \times 5^{\circ}$ in latitude and longitude, and approximately $300 \mathrm{~km}$ in height. Gusev landing site has a TES pixel that directly observe the landing site. 
Meridiani Planum (MER B / Opportunity Landing Site)

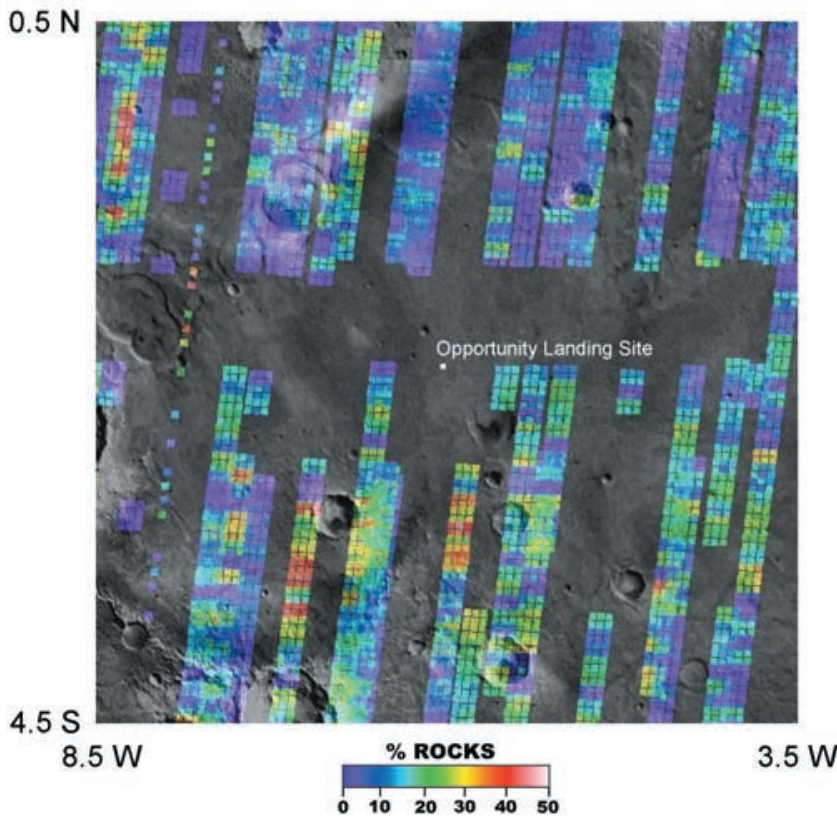

Figure 15. Rock abundance in the Opportunity/MER-B Mars landing site region. TES observations are represented by the $3 \times 3 \mathrm{~km}$ footprint of each detector draped over Viking photomosaics for context. Map is $5^{\circ} \times 5^{\circ}$ in latitude and longitude and approximately $300 \mathrm{~km}$ in height.

rockless and homogeneous on the large scale, with exposures of the underlying rock layers in impact craters [Squyres et al., 2004b]. Rock distribution observations from the perspective of a rover are only likely to result in a quantitative estimate that can be directly related to the regional value if the surfaces are homogeneous on the kilometer scale.

[74] The Pathfinder landing site at the mouth of Ares Vallis is a surface that was at least partly modified by the catastrophic flooding events from Ares and Tiu Vallis [Greeley et al., 1977; Golombek et al., 1997]. TES values near the Pathfinder landing site range from only a few percent to over $20 \%$, with a maximum over $35 \%$ in the region (Figure 16). The landing site pixel from TES is $12 \pm$ $4 \%$, while the IRTM value was found to be $18 \%$. Pathfinder rock count observations made with the visible camera resulted in a $19 \%$ areal coverage in the $3-6 \mathrm{~m}$ annulus around the lander [Golombek et al., 2003b].

[75] The Viking 1 landing site in Chryse Planitia was found to display a combination of drift and crusty materials superposed on a rocky substrate, most likely generated from impact events [Mutch et al., 1976a]. The observations of this site display the most discrepancy between the TES and IRTM data set, and the lowest TES rock abundance for all the sites. This is most likely a function of the distance between the landing site location and the closest measured values (Figure 17). The interpolated value gives an indication of the trend of surfaces in the region, but is probably not a good estimate for the fine-scale rockiness of the site. The TES interpolated value is $8 \pm 5 \%$, significantly lower than the IRTM value of $16 \%$. There was estimated to be $16 \%$ surface covered by rocks between .035 and .45 meters

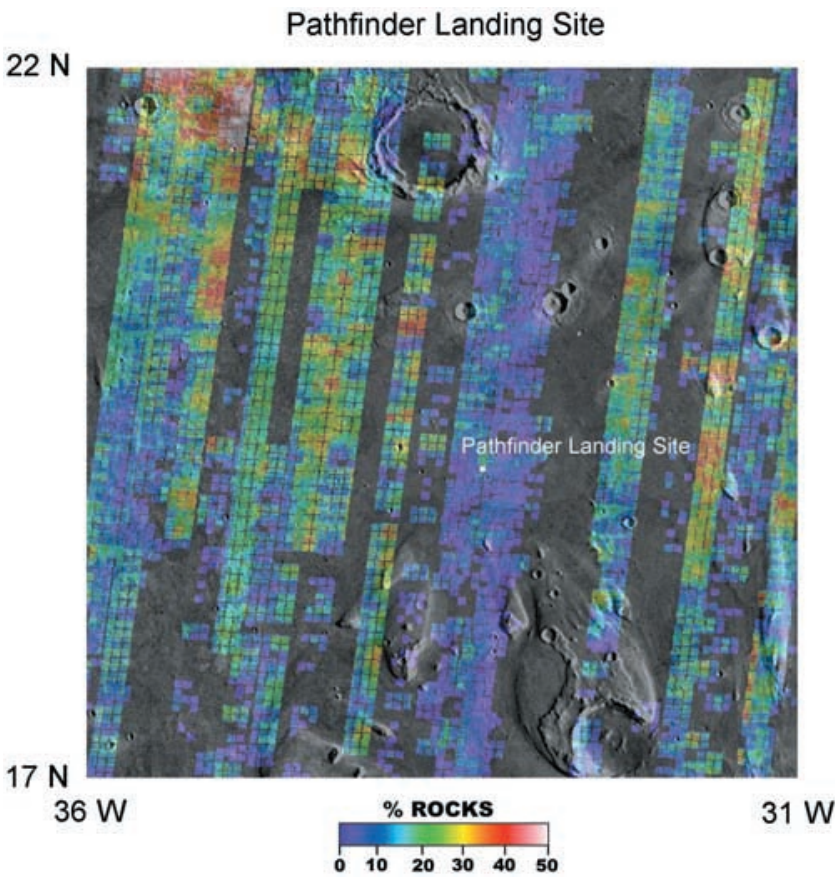

Figure 16. Rock abundance in the Mars Pathfinder landing site region. TES observations are represented by the $3 \times 3 \mathrm{~km}$ footprint of each detector draped over Viking photomosaics for context. Map is $5^{\circ} \times 5^{\circ}$ in latitude and longitude and approximately $300 \mathrm{~km}$ in height. The Pathfinder landing site has TES pixels that directly observe the landing site.

\section{Chryse Planitia (Viking 1 Landing Site)}

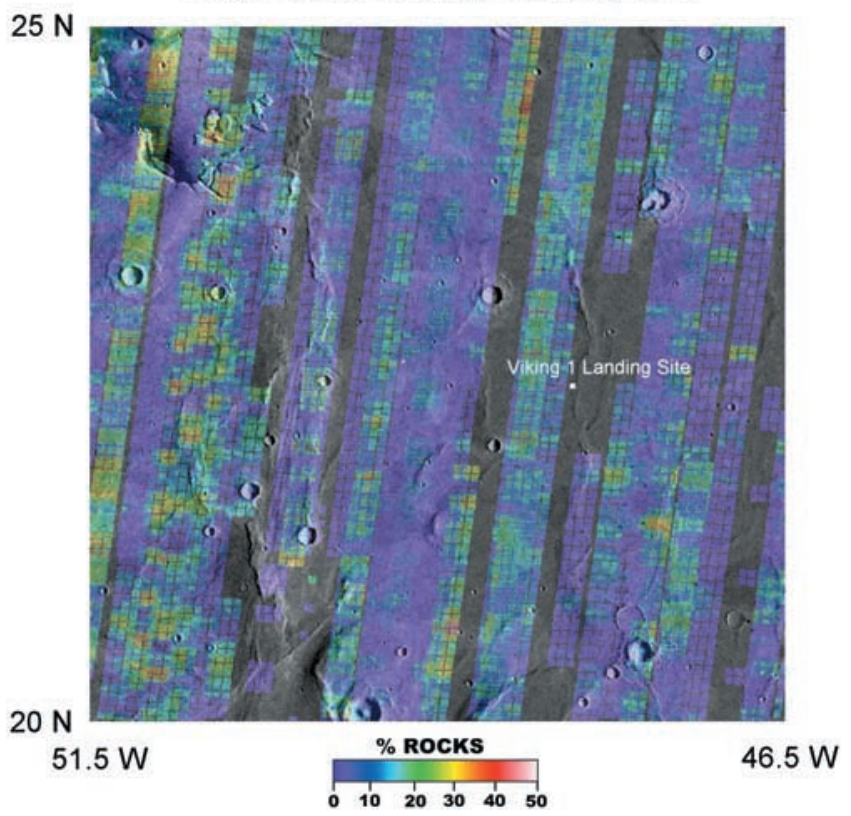

Figure 17. Rock abundance in the Viking 1 Mars landing site region. TES observations are represented by the $3 \times$ $3 \mathrm{~km}$ footprint of each detector draped over Viking photomosaics for context. Map is $5^{\circ} \times 5^{\circ}$ in latitude and longitude and approximately $300 \mathrm{~km}$ in height. 


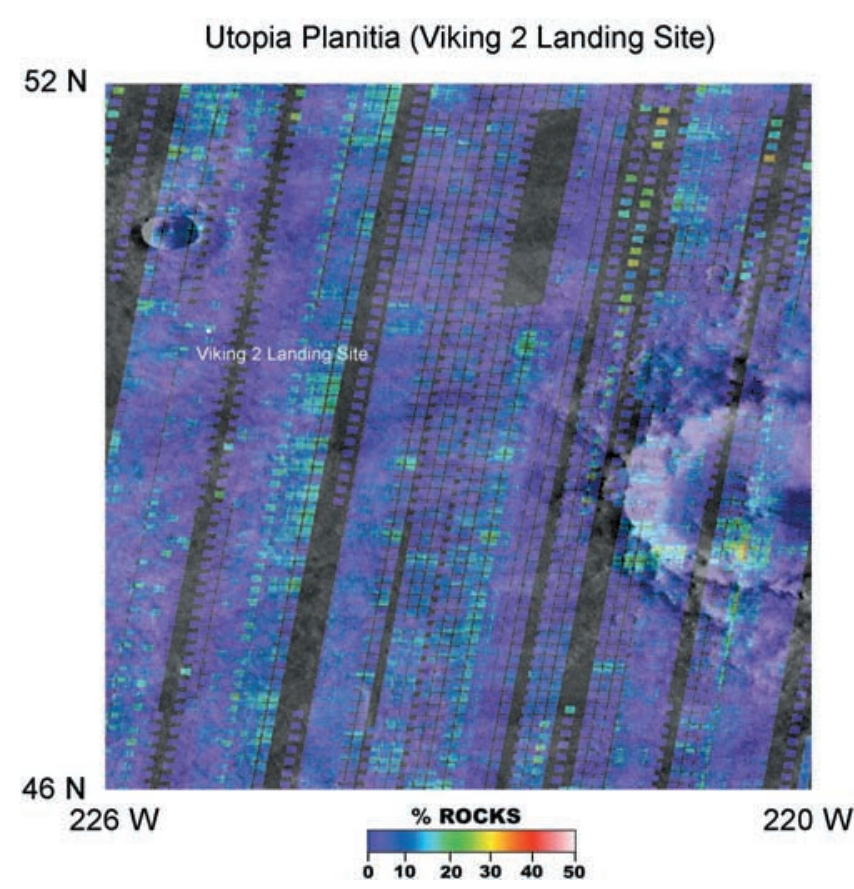

Figure 18. Rock abundance in the Viking 2 Mars landing site region. TES observations are represented by the $3 \times$ $3 \mathrm{~km}$ footprint of each detector draped over Viking photomosaics for context. Map is $5^{\circ} \times 5^{\circ}$ in latitude and longitude and is approximately $300 \mathrm{~km}$ in height. The Viking 2 landing site has TES pixels that directly observe the landing site.

at the VL1 and V12 landing sites, respectively [Moore and Keller, 1990, 1991].

[76] The Viking 2 landing site in Utopia Planitia is a relatively flat, extremely rocky surface [Mutch et al., 1976b], similar in bulk characteristics to the other rocky landing sites on Mars. The location of the VL2 landing site pushes the limit for surface temperature due to the high latitude, but a large number of TES observations are still available (Figure 18). The average rock abundance value from TES is $13 \pm 5 \%$, comparable to the IRTM value of $17 \%$. While the lander images show a relatively monotonous landscape, from an orbital view the region shows an extremely variable surface ranging from almost rockless to $20 \%$.

[77] The TES values for the landing sites are comparable to those calculated with the IRTM data set, given the spatial distribution of observations as seen in the images. The observations from most of the landers are near the uncertainties of TES observations, and indicative that these data are able to characterize local rock abundances. Although some of the lander rock counts include smaller clasts than can be identified as rocks using the TES algorithm, they each provide a similar measure of the site rockiness. This suggests that the TES rock abundance data are useful at the highest resolution and provide information that relates directly to physical measurements as could be made by a geologist or lander on the surface. Differences exist between binned values of IRTM and TES, but given the differences in pixel size and geometry of observations, it is not reasonable to expect perfect agreement between the two data sets.

\section{Conclusions}

[78] Nighttime infrared spectral observations returned from TES are well suited for determining the subpixel fraction of rocky material on the surface of Mars. The spectral difference algorithm used here determines both the areal fraction of rocks and the thermal inertia of the low-temperature nonrock component present in each field of view. These thermophysical properties provide information that can be combined with albedo and morphology to characterize surfaces and interpret the nature of the materials present.

[79] One of the major results from TES is that we are able to map rock and inertia values that are significantly higher and lower than observed with IRTM data [Christensen, 1986a]. The higher occurrences of both rocky $(>20 \%)$ and rockless surfaces $(0 \%)$ in TES data is primarily the result of the higher spatial resolution of the TES observations which can be used to distinguish specific units and surfaces that may have resulted from a single geological process. The expression of rocky surfaces is rarely controlled by morphology. Diffuse boundaries are common and provide evidence that recent eolian deflation or erosion exposed the rocks currently at the surface. The primary depositional process or mode of emplacement that formed or distributed rocks may be controlling the morphologies of the surfaces, but in many cases they have been subsequently modified by dust deposition, mechanical erosion, induration or a combination of these.

[80] A comparison of rock abundance and bolometric albedo shows an inverse relationship between rockiness and reflectivity, indicating that rocks are predominantly very dark. As part of the rock abundance algorithm, we assume that rocks are the lowest albedo materials on the surface, corresponding to dark basaltic blocks with an albedo of 0.1 [Christensen, 1982]. The bolometric observations provide an indication that this assumption holds true for the majority of the planet despite observations at landing sites where rocks are often covered by a thin layer of bright dust [Bell et al., 2004].

[81] Christensen [1986a] concluded that the finecomponent inertia controls the bulk thermal inertia for the majority of the planet. This is found to not be applicable for the highest-inertia units at TES resolution. Instead, a high fine-component inertia can generate bulk inertias in the $300 \mathrm{~J} \mathrm{~m}^{-2} \mathrm{~K}^{-1} \mathrm{~s}^{-1 / 2}$ range, and rocks are required to increase the inertia above that level. Mars can thus be modeled with three primary thermophysical components: dust $\left(<150 \mathrm{~J} \mathrm{~m}^{-2} \mathrm{~K}^{-1} \mathrm{~s}^{-1 / 2}\right)$, a variable moderate inertia component (up to $\sim 300 \mathrm{~J} \mathrm{~m}^{-2} \mathrm{~K}^{-1} \mathrm{~s}^{-1 / 2}$ ), and rocks $\left(>1250 \mathrm{~J} \mathrm{~m}^{-2} \mathrm{~K}^{-1} \mathrm{~s}^{-1 / 2}\right)$. Combinations of these three components can be used to model the complex surfaces observed on Mars.

[82] Acknowledgments. The research was made possible thanks to the contributions of the TES science team and the continued efforts of the operations staff at Arizona State University. H. H. Kieffer provided the KRC thermal model used in the surface temperature calculations, a derivation of the original Mariner 9 model. J. L. Bandfield provided the atmospheric radiance correction and insight into atmospheric modeling 
using TES. This work was supported by the Mars Global Surveyor Project Office.

\section{References}

Bandfield, J. L. (2002), Global mineral distributions on Mars, J. Geophys. Res., 107(E6), 5042, doi:10.1029/2001JE001510.

Bandfield, J. L., and M. D. Smith (2003), Multiple emission angle surfaceatmosphere separations of Thermal Emission Spectrometer data, Icarus, $161,47-65$

Bandfield, J. L., P. R. Christensen, and M. D. Smith (2000), Spectral dataset factor analysis and endmember recovery: Application to Martian atmospheric particulates, J. Geophys. Res., 105, 9573-9588.

Bell, J. F., III, et al. (2004), Pancam multispectral imaging results from the Spirit rover at Gusev Crater, Science, 305, 800-806.

Betts, B. H., B. C. Murray, and T. Svitek (1995), Thermal inertia in the upper millimeters of the Martian surface derived using Phobos' shadow, J. Geophys. Res., 100, 5285-5296.

Boynton, W. V., et al. (2002), Distribution of hydrogen in the near surface of Mars: Evidence for subsurface ice deposits, Science, 297, 81-85.

Cabrol, N. A., E. A. Grin, and G. Dawidowicz (1996), Ma'adim Vallis revisited through new topographic data: Evidence for an ancient intravalley lake, Icarus, 123, 269-283.

Christensen, P. R. (1982), Martian dust mantling and surface composition: Interpretation of thermophysical properties, J. Geophys. Res., 87, 99859998.

Christensen, P. R. (1986a), The spatial distribution of rocks on Mars, Icarus, 68, 217-238.

Christensen, P. R. (1986b), Regional dust deposits on Mars, J. Geophys. Res., 91, 3533-3545.

Christensen, P. R. (1999), Calibration report for the Thermal Emission Spectrometer (TES) for the Mars Global Surveyor Mission, Mars Global Surveyor Project, Jet Propul. Lab., Pasadena, Calif.

Christensen, P. R., and M. C. Malin (1988), High-resolution thermal imaging of Mars, Lunar Planet. Sci., XIX, 180-181.

Christensen, P. R., et al. (1998), Results from the Mars Global Surveyor Thermal Emission Spectrometer, Science, 279(5357), 1692-1698.

Christensen, P. R., et al. (2000), Detection of crystalline hematite mineralization on Mars by the Thermal Emission Spectrometer: Evidence for near-surface water, J. Geophys. Res., 105, 9623-9642.

Christensen, P. R., et al. (2001), The Mars Global Surveyor Thermal Emission Spectrometer Experiment: Investigation description and surface science results, J. Geophys. Res., 106, 23,823-23,871.

Christensen, P. R., et al. (2004), Initial results from the Mini-TES experiment in Gusev crater from the Spirit rover, Science, 305, 837-842.

Clancy, R. T., B. J. Sandor, M. J. Wolff, P. R. Christensen, M. D. Smith, J. C. Pearl, B. J. Conrath, and R. J. Wilson (2000), An intercomparison of ground-based millimeter, MGS TES, and Viking atmospheric temperature measurements: Seasonal and interannual variability of temperatures and dust loading in the global Mars atmosphere, J. Geophys. Res., 105 , 9553-9571.

Conrath, B. J., J. C. Pearl, M. D. Smith, W. C. Maguire, P. R. Christensen, S. Dason, and M. S. Kaelberer (2000), Mars Global Surveyor Thermal Emission Spectrometer (TES) observations: Atmospheric temperatures during aerobraking and science phasing, J. Geophys. Res., 105, 95099519.

Crumpler, L. S., et al. (2005), Mars Exploration Rover geologic traverse by the Spirit rover in the plains of Gusev Crater, Mars, Geology, 33, 809812.

de Vaucouleurs, G. (1967), A low-resolution photometric map of Mars, Icarus, 7, 310-349.

Feeley, K. C., and P. R. Christensen (1999), Quantitative compositional analysis using thermal emission spectroscopy: Application to igneous and metamorphic rocks, J. Geophys. Res., 104, 24,195-24,210.

Feldman, W. C., et al. (2002), Global distribution of neutrons from Mars: Results from Mars Odyssey, Science, 297.

Fergason, R. L., and P. R. Christensen (2003), Thermal inertia using THEMIS infrared data, Lunar Planet. Sci., XXXI, Abstract 1785.

Fergason, R. L., P. R. Christensen, J. F. Bell III, M. P. Golombek, K. E. Herkenhoff, and H. H. Kieffer (2006), Physical properties of the Mars Exploration Rover landing sites as inferred from Mini-TES-derived thermal inertia, J. Geophys. Res., 111, E02S21, doi:10.1029/ 2005JE002583.

Gillespie, A. R. (1992), Spectral mixture analysis of multispectral thermal infrared images, Remote Sens. Environ., 42, 137-145.

Golombek, M. P., and D. Rapp (1997), Size-frequency distributions of rocks on Mars and Earth analog sites: Implications for future landed missions, J. Geophys. Res., 102, 4117-4129.

Golombek, M. P., et al. (1997), Overview of the Mars Pathfinder mission and assessment of landing site predictions, Science, 278, 1743-1748.
Golombek, M. P., A. F. C. Haldemann, N. K. Forsberg-Taylor, E. N. DiMaggio, R. D. Schroeder, B. M. Jakosky, M. T. Mellon, and J. R. Matijevic (2003a), Rock size-frequency distributions on Mars and implications for Mars Exploration Rover landing safety and operations, J. Geophys. Res., 108(E12), 8086, doi:10.1029/2002JE002035.

Golombek, M. P., et al. (2003b), Selection of the Mars Exploration Rover landing sites, J. Geophys. Res., Planets, 108(E12), 8072.

Golombek, M., et al. (2005), Assessment of Mars Exploration Rover landing site predictions, Nature, 436, 44-48

Golombek, M. P., et al. (2006), Geology of the Gusev cratered plains from the Spirit rover traverse, J. Geophys. Res., 111, E02S07, doi:10.1029/ 2005JE002503.

Grant, J. A., et al. (2004), Surficial deposits at Gusev crater along Spirit rover traverses, Science, 305, 807-810.

Greeley, R., E. Theilig, J. E. Guest, M. H. Carr, H. Masursky, and J. A. Cutts (1977), Geology of Chryse Planitia, J. Geophys. Res., 82, 4093-4109.

Greeley, R., A. Skypeck, and J. B. Pollack (1993), Martian aeolian features and deposits: Comparisons with general circulation model results, J. Geophys. Res., 98, 3183-3196.

Haberle, R. M., and B. M. Jakosky (1991), Atmospheric effects on the remote determination of thermal inertia on Mars, Icarus, 90, 187-204.

Hamilton, V. E., and P. R. Christensen (2000), Determining the modal mineralogy of mafic and ultramafic igneous rocks using thermal emission spectroscopy, J. Geophys. Res., 105, 9717-9734.

Hayashi, J. N., B. M. Jakosky, and R. M. Haberle (1995), Atmospheric effects on the mapping of Martian thermal inertia and thermally derived albedo, J. Geophys. Res., 100, 5277-5284.

Jaeger, J. C. (1953), The surface temperature of the Moon, Aust. J. Phys., 6, $10-21$.

Jakosky, B. M. (1986), On the thermal properties of Martian fines, Icarus, $66,117-124$

Jakosky, B. M., and P. R. Christensen (1986), Global duricrust on Mars: Analysis of remote sensing data, J. Geophys. Res., 91, 3547-3559.

Jakosky, B. M., M. T. Mellon, H. H. Kieffer, P. R. Christensen, E. S. Varnes, and S. W. Lee (2000), The thermal inertia of Mars from the Mars Global Surveyor Thermal Emission Spectrometer, J. Geophys. Res., 105, 9643-9652.

Keller, J. M., et al. (2003), Preliminary correlations of Mars GRS elemental abundances with thermal inertia, albedo, and rock abundance, Lunar Planet. Sci., XXXIV, Abstract 2021.

Kieffer, H. H., S. C. Chase, E. Miner, G. Munch, and G. Neugebauer (1973), Preliminary report on infrared radiometric measurements from the Mariner 9 spacecraft, J. Geophys. Res., 78, 4291-4312.

Kieffer, H. H., T. Z. Martin, A. R. Peterfreund, B. M. Jakosky, E. D. Miner, and F. D. Palluconi (1977), Thermal and albedo mapping of Mars during the Viking primary mission, J. Geophys. Res., 82, 4249-4290.

Leovy, C. (1966), Note on the thermal properties of Mars, Icarus, 5, $1-6$. Mellon, M. T., B. M. Jakosky, H. H. Kieffer, and P. R. Christensen (2000), High resolution thermal inertia mapping from the Mars Global Surveyor Thermal Emission Spectrometer, Icarus, 148, 437-455.

Mellon, M. T., W. C. Feldman, and T. H. Prettyman (2004), The presence and stability of ground ice in the southern hemisphere of Mars, Icarus, $169,324-340$

Mitrofanov, I., et al. (2002), Maps of subsurface hydrogen from the high energy neutron detector, Mars Odyssey, Science, 297, 78-81.

Moore, H. J., and J. M. Keller (1989), Surface-material maps of the Viking landing sites on Mars, NASA Tech. Mem., NASA TM-4300, 533-535.

Moore, H. J., and J. M. Keller (1990), Surface-material maps of the Viking landing sites on Mars, NASA Tech. Mem., NASA TM-4210, 160-162.

Moore, H. J., and J. M. Keller (1991), Surface-material maps of Viking landing sites on Mars, Rep. Planet. Geol. Geophys. Program, 1990, $160-$ 162 .

Moore, H. J., C. R. Spitzer, K. Z. Bradford, P. M. Cates, R. W. Shorthill, and R. E. Hutton (1979), Sample fields of the Viking landers, physical properties, and aeolian processes, J. Geophys. Res., 84, 8365-8377.

Mutch, T. A., A. B. Binder, F. O. Huck, E. C. Levinthal, S. Liebes Jr., E. C. Morris, W. R. Patterson, B. Pollack, C. Sagan, and G. R. Taylor (1976a), The surface of Mars-The view from the Viking 1 lander, Science, 193, $791-801$.

Mutch, T. A., S. U. Grenander, K. L. Jones, W. Patterson, R. E. Arvidson, E. A. Guinness, P. Avrin, C. E. Carlston, A. B. Binder, and C. Sagan (1976b), The surface of Mars-The view from the Viking 2 lander, Science, 194, 1277-1283.

Neugebauer, G., G. Munch, H. H. Kieffer, S. C. Chase, and E. Miner (1971), Mariner 1969 infrared radiometer results: Temperatures and thermal properties of the Martian surface, Astron. J., 76(8), 719-721.

Palluconi, F. D., and H. H. Kieffer (1981), Thermal inertia mapping of Mars from $60 \mathrm{~S}$ to $60 \mathrm{~N}$, Icarus, 45, 415-426.

Pearl, J. C., M. D. Smith, B. J. Conrath, J. L. Bandfield, and P. R. Christensen (2001), Observations of Martian ice clouds by the Mars 
Global Surveyor Thermal Emission Spectrometer: The first Martian year, J. Geophys. Res., 106, 12,325-12,338.

Pollack, J. B., D. S. Colburn, F. M. Flasar, R. Kahn, C. E. Carlston, and D. G. Pidek (1979), Properties and effects of dust particles suspended in the Martian atmosphere, J. Geophys. Res., 84, 2929-2945.

Presley, M. A., and P. R. Christensen (1997), Thermal conductivity measurements of particulate materials: 2. Results, J. Geophys. Res., 102, 6551-6566.

Putzig, N. E., M. T. Mellon, K. A. Kretke, and R. E. Arvidson (2005), Global thermal inertia and surface properties of Mars from the MGS mapping mission, Icarus, 173, 325-341.

Ramsey, M. S., and P. R. Christensen (1998), Mineral abundance determination: Quantitative deconvolution of thermal emission spectra, J. Geophys. Res., 103, 577-596.

Ramsey, M. S., and J. H. Fink (1999), Estimating silicic lava vesicularity with thermal remote sensing: A new technique for volcanic mapping and monitoring, Bull. Volcanol., 61, 32-39.

Ramsey, M. S., P. R. Christensen, N. Lancaster, and D. A. Howard (1999), Identification of sand sources and transport pathways at the Kelso dunes, California, using thermal infrared remote sensing, Geol. Soc. Am. Bull., $111,646-662$

Selivanov, A. S., M. K. Naraeva, A. S. Panfilov, Y. M. Gektin, V. D. Kharlamov, A. V. Romanov, D. A. Fomin, and Y. Miroshnichenko (1989), Thermal imaging of the surface of Mars, Nature, 341, 593-595.

Smith, M. D. (2004), Interannual variability in TES atmospheric observations of Mars during 1999-2003, Icarus, 167, 148-165.

Smith, M. D., J. L. Bandfield, and P. R. Christensen (2000), Separation of atmospheric and surface spectral features in Mars Global Surveyor Ther- mal Emission Spectrometer (TES) spectra, J. Geophys. Res., 105, 9589_ 9607.

Smith, M. D., J. C. Pearl, B. J. Conrath, and P. R. Christensen (2001), One Martian year of atmospheric observations by the Thermal Emission Spectrometer, Geophys. Res. Lett., 28, 4263-4266.

Squyres, S. W., et al. (2003), Athena Mars Rover science investigation, J. Geophys. Res., 108(E12), 8062, doi:10.1029/2003JE002121.

Squyres, S. W., et al. (2004a), The Spirit rover's Athena Science Investigation at Gusev Crater, Mars, Science, 305, 794-799.

Squyres, S. W., et al. (2004b), The Opportunity rover's Athena Science Investigation at Meridiani Planum, Mars, Science, 306, 1698-1703.

Thompson, J. L., and J. W. Salisbury (1993), The mid-infrared reflectance of mineral mixtures $(7-14 \mu \mathrm{m})$, Remote Sens. Environ., 45, 1-13.

Tillman, J. E., N. C. Johnson, P. Guttorp, and D. B. Percival (1993), The Martian annual atmospheric pressure cycle-Years without great dust storms, J. Geophys. Res., 98, 10,963-10,971.

Wechsler, A. E., and P. E. Glaser (1965), Pressure effects on postulated lunar materials, Icarus, 4, 335-352.

Wechsler, A. E., P. E. Glaser, and J. A. Fountain (1972), Thermal properties of granulated materials, in Thermal Characteristics of the Moon, pp. 215-241, MIT Press, Cambridge, Mass.

Wesselink, A. J. (1948), Heat conductivity and nature of the lunar surface material, Bull. Astron. Inst. Neth., 10, 351-363.

P. R. Christensen and S. A. Nowicki, Department of Geological Sciences, Arizona State University, Box 6305, Tempe, AZ 85287, USA. (snowicki@ asu.edu) 